\title{
Objets du quotidien à Damas à l'époque ottomane
}

Objects of Everyday Life in Ottoman Damascus

$$
\text { الأشياء اليومية في دمشق في العصر العثماني }
$$

\section{Véronique François}

\section{OpenEdition \\ Journals}

Édition électronique

URL : http://journals.openedition.org/beo/1038

DOI : 10.4000/beo.1038

ISBN : 978-2-35459-347-9

ISSN : 2077-4079

Éditeur

Presses de l'Institut français du Proche-Orient

\section{Édition imprimée}

Date de publication : 1 décembre 2012

Pagination : 475-506

ISBN : 978-2-35159-379-0

ISSN : 0253-1623

Référence électronique

Véronique François, "Objets du quotidien à Damas à l'époque ottomane », Bulletin d'études orientales [En ligne], Tome LXI | décembre 2012, mis en ligne le 20 mars 2013, consulté le 30 avril 2019. URL : http://journals.openedition.org/beo/1038; DOI : 10.4000/beo.1038 


\section{Objets du quotidien à Damas à l'époque ottomane}

Véronique FRAC ÇOIS

L'exploration archéologique de la citadelle de Damas conduite par une équipe francosyrienne, entre 1999 et 2003, a livré des informations nouvelles quant à l'occupation de ce complexe militaire à l'époque ottomane. Les textes, complétés par les fouilles et par l'étude du mobilier céramique très abondant, permettent non seulement de retracer l'histoire de cette grande forteresse urbaine entre le XVI et la fin du XIx siècle mais révèlent également quelques aspects de la vie quotidienne des janissaires, des commerçants, des artisans et de leurs familles installés à l'intérieur de l'enceinte.

\section{Une ville-garnison fouillée partiellement}

La citadelle de Damas, située dans le quartier nord-ouest de la vieille ville, construite en terrain plat et prise dans un tissu urbain dense, couvre une superficie de 4 hectares (pl. 1). Cette énorme fortification militaire arabe a été le lieu d'exercice du pouvoir politique en Syrie centrale entre le XI ${ }^{\mathrm{e}}$ et le XIII ${ }^{\mathrm{e}}$ siècle puis le siège et la résidence du pouvoir administratif et militaire aux époques mamelouke et ottomane. Tout au long de l'époque ottomane, les bâtiments à caractère défensif de la citadelle - le mur d'enceinte ainsi que les tours - ont été l'objet de dégradations répétées ${ }^{1}$ et les fonctions militaires de cet ensemble se sont peu à peu amoindries. Dès le début du Xvi ${ }^{e}$ siècle, la citadelle abritait une mosquée, un hammam, un moulin et des boutiques, des citernes ainsi que diverses bâtisses ${ }^{2}$. À partir de 1659, cette fortification qui servait de garnison aux janissaires impériaux ${ }^{3}$ s'est progressivement transformée en ville-garnison. Dans la deuxième moitié du XviI siècle, d'Arvieux (16351702) y a repéré des logements bien que, dans sa description, il s'attarde davantage sur les bâtiments officiels.

\footnotetext{
1. Ces dégradations ont été causées par: des conflits entre les janissaires et les milices locales, par des luttes armées entre ancien et nouveau gouverneur, par les attaques des Mamelouks d'Égypte, de potentats régionaux et de Bédouins, et, en 1759, par un tremblement de terre.

2. Selon l'Égyptien al-Badrī cité dans ZiAdeH 1982, p. 38.

3. Le corps des janissaires impériaux (kapı kulu), dont une partie seulement résidait à la citadelle, et les janissaires locaux comptaient, selon les estimations, entre 300 et 2000 membres. Establet \& PAsCUAL 1994, p. 11, 18, 19.
} 
« en entrant [on voit] un grand et spacieux corps de garde bien voûté et fort propre dont les murailles sont toutes couvertes d'armes antiques et modernes en bon ordre et fort bien entretenues... Un peu plus avant on voit un corps de logis appelé Cassaba, où l'on bat la monnaie [probablement la salle à colonnes ${ }^{4}$ ], à côté duquel il y a un dôme assez vaste et tout ouvert, qui est soutenu par quatre piliers d'une grosseur si démesurée, que je crois qu'ils porteraient la coupole de St Pierre de Rome. La grande salle du conseil est au fond de la cour; elle est voûtée et peinte en or et en azur, avec quelques passages de l'Alcoran, qui regardent la justice qu'on y rend. On l'appelle à cause de cela le Divan. Les deux côtés de la cour sont des bâtiments assez propres séparés les uns des autres par de petites rues; ils servent de logements aux officiers et aux janissaires qui composent la garnison. Et comme ils sont voûtés et en terrasse, et appuyés la plupart contre les murs du château, ils leur servent de rempart. Au reste ces murs n'ont qu'environ une toise d'épaisseur, et les pierres de taille font parpain. Voilà tout ce que je pus voir de ce château, le reste est inaccessible » ${ }^{5}$.

$\mathrm{Au}$ XVIII ${ }^{\mathrm{e}}$ siècle, les sources témoignent de l'ouverture de la citadelle aux civils. Les janissaires qui y vivaient avec leurs familles ont été rejoints par des artisans et par des commerçants - un armurier était domicilié à la Qal'at Dimašq, la Citadelle de Damas ${ }^{6}$, et les archives livrent le nom d'un épicier ${ }^{7}$. De nombreux documents, relatifs aux maisons - dans les années 1760-1774, deux militaires et deux civils y possédaient une habitation et aux cafés (qahwa hānah) construits à l'intérieur de l'enceinte, sont consignés dans les registres des tribunaux de Damas ${ }^{8}$. La citadelle était un centre d'affaires aussi bien pour les militaires que pour les civils ${ }^{9}$ et, selon R. Pococke (1704-1765), «the castle (...) appears within like a little town, and one sees nothing of the form of a castle ${ }^{10}$. En 1812, alors qu'on y dénombrait encore cent quatre-vingts janissaires, un conflit entre le nouveau gouverneur de Damas, Sulaymān Pacha al-Silaḥdār, et l'Ag̉a de la citadelle, dégénérant en bataille rangée, a causé d'importantes dégradations aux bâtiments situés à l'intérieur de l'enceinte ${ }^{11}$. La citadelle a été de nouveau bombardée en 1831, lors d'une nouvelle insurrection menée contre le gouverneur Salīm Pacha ${ }^{12}$. Les importants dommages subis par les constructions sont décrits par le voyageur anglais E. Hogg qui constatait, consterné, l'état de délabrement des bâtiments ${ }^{13}$. Des vestiges de plafonds de bois peints et sculptés, des restes de pavements de marbre, des portes sculptées, des fragments de fresques colorées, des décors incrustés et dorés, ainsi que des fontaines brisées témoignaient alors de la splendeur passée des lieux. À partir de cette époque, la citadelle a été transformée en une sorte d'entrepôt. Sa

\footnotetext{
4. Des vestiges d'un atelier ont effectivement été mis au jour dans la salle à colonnes.

5. D’ARVIEUX 1982, p. 199-200.

6. Marino 1997, p. 164 ; Establet et Pascual 1994, p. 156, tableau 52.

7. Establet \& PASCUAL 1994, p. 81, 155 ; RAFEQ 1981, p. 657.

8. Merci à Brigitte Marino (CNRS-IREMAM, MMSH, Aix-en-Provence) pour cette information.

9. Le salaire des janissaires était touché par l'inflation. Les militaires se sont alors engagés dans le commerce et dans l'artisanat. Certains ont acquis des biens fonciers tandis que d'autres sont devenus usuriers. PAscuAL 1983 , p. 8.

10. POCOCKE 1745, p. 119.

11. CHeVedden 1986, p. 133-134.

12. Ibidem, p. 134-136.

13. Cité dans Chevedden 1986, p. 136-137.
} 
démilitarisation progressive était sans doute liée à la construction, dès 1860, de plusieurs casernes et autres dépôts de munitions dispersés dans la ville ${ }^{14}$. À la fin du XIX ${ }^{e}$ siècle, selon le scientifique français Louis Charles Émile Lortet (1836-1909), le «château est aujourd'hui transformé en arsenal, que nous n'avons pas pu visiter mais qui renferme, paraît-il, un grand nombre d'armes du moyen âge prises par les musulmans sur les armées des croisades (...) Les terrasses supérieures portent quelques vieux canons turcs. Cette forteresse n'a jamais pu être explorée sérieusement, elle présente à ce que l'on m'a dit, de nombreuses salles, des réduits obscurs et de vastes souterrains» ${ }^{15}$. Tandis que l'enceinte restait imposante, l'intérieur, ruiné, n'était plus occupé que par une poignée d'hommes. Et en 1895, alors que l'immense caserne Hamīdiyya était en construction, les fossés de la citadelle ont été comblés ${ }^{16}$.

Dès la fin des années 1980, les services archéologiques syriens ont ouvert, à l'intérieur de l'enceinte, une série de sondages. Et, en 1999, à la demande de la Direction générale des Antiquités et des Musées de Syrie (DGAMS), un programme de recherche franco-syrien a débuté à la citadelle ${ }^{17}$. Dirigée conjointement par Sophie Berthier, alors chercheur à l'Institut français d'études arabes, et Ahmad Taraqji puis Edmond El-Ajji, respectivement archéologue et ingénieur à la DGAMS, cette mission archéologique avait pour objectif d'intervenir en amont de l'entreprise de restauration de la citadelle ${ }^{18}$. Un peu plus de $1600 \mathrm{~m}^{2}$ ont ainsi été explorés; ils ont livré une grande quantité de poterie. Au total, ce sont huit mille fragments de céramique d'époque ottomane qui ont été mis au jour, deux mille d'entre eux ont servis à l'élaboration de la typologie ${ }^{19}$. Ces poteries proviennent de quatre zones principales : d'une maison à cour avec un bassin et des latrines qui étaient sans doute un casernement ou un habitat militaire au xvIII ${ }^{e}$ siècle, localisée dans le cadrant nord-est du site entre la grande galerie et le mur d'enceinte nord ( $\mathrm{pl}$. 1, zone 1 sur le plan) ; de maisons construites sur la porterie nord au XviIle siècle (pl.1, zone 13); d'un dépôt, scellé au xvIII ${ }^{e}$ siècle, dans un escalier obturé entre le premier et le deuxième étage de la tour 4 (pl. 1, zone T4); de plusieurs niveaux, du XIXe-début $\mathrm{xx}^{\mathrm{e}}$ siècle, au premier étage du «bâtiment sud-ouest » (pl. 1, zone 5).

La céramique culinaire, les jarres de stockage et la vaisselle de service et de table produites au Bilād al-šām ainsi que la poterie importée témoignent, tout au long de la période ottomane, d'un approvisionnement varié à travers lequel il est possible d'appréhender le mode de vie d'une partie des occupants installés à l'intérieur de l'enceinte et de reconnaître

\footnotetext{
14. ARNAUD 2006, p. 135, note 104.

15. LORTET 1884, p. 596-597.

16. ARNAUD 2006, p. 135.

17. Sur l'exploration archéologique de la citadelle voir BERTHIER \& EL-AJJI 2002.

18. Rien n'aurait pu se faire sans la grande bienveillance accordée à la fouille par la Direction Générale des Antiquités et des Musées de Syrie et ses directeurs successifs - Messieurs Sultan Muhesen, Abderrazzaq Moaz, Tammam Facouche et Bassam Jamous.
}

19. FRANçoIs 2008a. 
les courants commerciaux qui ont alimenté le marché de la vaisselle du Xvie siècle jusqu'à la fin du XIX ${ }^{\mathrm{e}}$ siècle.

\section{Des objets de la vie quotidienne}

Ces découvertes archéologiques concernent à peu près tous les milieux et offrent un panorama assez vaste des objets employés pour le transport des denrées, leur stockage, la préparation des mets et leur service ainsi que pour l'éclairage. Elles renseignent aussi sur le niveau social des habitants à travers les importations de vaisselle étrangère et la taille des pipes à tabac. Elles livrent enfin des informations rares sur des pratiques propitiatoires.

Le croisement des données matérielles avec les sources écrites - des inventaires après décès, des documents d'archives judiciaires, des récits de voyageurs, des archives consulaires, un dictionnaire de l'artisanat ${ }^{20}$ - permet de mieux cerner la nature des objets et de déterminer leur usage. Cependant, il n'est pas toujours aisé de rapprocher les céramiques des termes qui les désignent et il faut se garder de croire qu'à chaque forme correspondait un emploi. La plupart des ustensiles pouvaient avoir des usages multiples. Dans ce cadre et à l'intérieur de ces limites, il est possible d'appréhender le quotidien des habitants de la citadelle.

\section{Cuisiner, conserver et servir}

Les découvertes archéologiques et les textes en témoignent, dans l'Empire ottoman, une grande partie du vaisselier de terre employé jusque là a cédé peu à peu la place aux ustensiles de métal. Pour la cuisson bouillie ou frite, pour le service des mets et des liquides, pour l'hygiène et les ablutions, les récipients de cuivre et de cuivre étamé étaient en effet partout présents, chez les pauvres comme chez les riches, dans les cuisines du Palais impérial comme dans les intérieurs damascènes. À Istanbul, les bakırdjı fabriquaient des chaudrons, des ustensiles de cuisine, des récipients et des pièces de vaisselle variées en cuivre ainsi qu'en laiton et en étain ${ }^{21}$. Les étameurs ottomans étaient d'ailleurs admirés par les Occidentaux. De Tournefort (1656-1708) rapportait que «leur vaisselle (...) la plus commune est de cuivre étamé (...) Ils l'étament fort proprement et très promptement, en faisant rougir au feu les pièces de vaisselle; ils les saupoudrent pour lors avec du sel ammoniaque, et ils y appliquent ensuite des boutons d'étain qu'ils étendent avec un brunissoir; cet étain s'attache si bien au cuivre que leur vaisselle ne rougit pas aussi facilement que la nôtre $"{ }^{22}$. L'étamage régulier des marmites était la garantie d'une bonne hygiène de la cuisine et le règlement des muhtasib-s (inspecteurs des marchés) d'Istanbul en 1660 prescrivait «Que les mets préparés par les cuisiniers ne soient pas mal cuits,

20. À l'exception des récits de voyageurs, je n'ai pas exploité moi-même les sources primaires. J'ai repris les informations relatives à la vaisselle dans les études menées principalement par C. Establet et J.-P. Pascual, B. Marino, R. Mantran, M. Milwright et E. Doutté.

21. HitZEL 2007, p. 98.

22. DE TOURNEFORT 1982, I, p. 98. 
ni trop salés; que leurs écuelles soient propres, leurs chaudrons étamés, leurs plats de terre neufs et luisants comme le verre $"{ }^{23}$. À Topkap1 Sarayı, au XvIII ${ }^{e}$ siècle, le chef du cellier impérial avait sous ses ordres des étameurs d'ustensiles en cuivre à qui étaient régulièrement attribués étain et sel ammoniac ${ }^{24}$. L'utilisation de divers types de plats de cuivre (suhūn nuhāss) est également attestée, à Damas, à travers les inventaires après décès - pour la cuisson bouillie des mets, des marmites (tanğara) et, pour la cuisson frite, des poêlons (tawā, luhūq ou miqlāya) - et dans plusieurs documents juridiques établis à partir de 1691. Il existait en effet, à la citadelle, « un waqf de la vaisselle » fondé par le gouverneur Ipš̄ir Mușțafā Pacha ${ }^{25}$. En 1722, trois cent vingt-cinq plats métalliques étaient recensés : 200 avec piédouche (muka"ab) et 125 sans piédouche (bi-lā takîib). On y trouvait aussi un demi-quintar de plats cassés (suhūn mukassara). Plus de six cents plats étaient enfermés dans un dépôt scellé. En 1725, le gestionnaire du waqf dénombrait six cent treize plats en cuivre - trois cent un intacts (suhūn sahihha) et deux cent dix-sept endommagés (mukassara sahïha) - et distinguait les plats bas (wātiya) des plats hauts ('äliya). Il était également question de plats de sable (ramliyya), un qualificatif sans doute à mettre en rapport avec le procédé de fabrication de ces objets coulés dans des moules de sable. Les plats cassés et endommagés étaient vendus au poids pour permettre l'achat d'ustensiles neufs, en cuivre également. Il existait, au nord de la citadelle, au moins depuis l'époque mamelouke, un souk spécialisé dans la fabrication d'ustensiles de cuisine en cuivre - le Sūq al-Naḥhāsīn - tandis que d'autres dinandiers exerçaient également dans le faubourg du Mīdān ${ }^{26}$. Au $\mathrm{XIX}^{\mathrm{e}}$ siècle, de nombreux artisans y battaient toujours le cuivre pour réaliser des casseroles, des poêles, des plats, des bassins et des passoires tandis que les samkarī étamaient des ibrīq, des salières, des cafetières et des samovars comme le rapporte le Dictionnaire des métiers ${ }^{27}$.

Les ustensiles culinaires métalliques étaient le plus souvent refondus après usage comme en attestent d'ailleurs les documents relatifs au «waqf de la vaisselle ». Ils sont donc très rarement retrouvés au cours des fouilles archéologiques. C'est pourquoi il est impossible, à partir des seuls vestiges, d'estimer la part relative occupée par les ustensiles métalliques et les poteries. À la citadelle, ce qui est surprenant c'est l'absence, dans les nivaux ottomans, de céramique culinaire. Dans les cuisines des casernements ainsi que dans les maisons des particuliers, les marmites de terre et autres pots à cuire, nombreux à l'époque mamelouke, ont manifestement cédé la place à leurs homologues de métal, des chaudrons, de grandes casseroles et des poêles. Cependant, comme le montrent les archives du xvIII siècle, dans les batteries de cuisine et de service des maisons damascènes, aisées ou

\footnotetext{
23. MANTRAN 1962, p. 330-335.

24. INALCIK 1991, p. 800 ; SAMANCI 2009, p. 157.

25. Ces informations m'ont été transmises par Brigitte Marino que je remercie.

26. MARINo 1997, p. 182.

27. Le Dictionnaire des Métiers ou Qāmūs al-șinā'āt al-šāmiyya est une compilation écrite entre 1891 et 1905 par Muhammad Sa īd al-Qāsimī, Ǧamāl al-Dīn al-Qāsimī et Hֵalīl al-'Aẓm. Elle a été publiée pour la première fois en 1960. AL-QASIMI 1960, p. 479-480. Pour une traduction de ce passage voir MiLWRIGHT sous presse.
} 
plus modestes, la dinanderie côtoyait encore la poterie ${ }^{28}$. Des objets de même fonction étaient apparemment réalisés en terre ou en métal. Ainsi sur les vingt-six aiguières (ibrīq) recensées dans l'inventaire après décès du Šayh 'Alī, treize étaient en terre et treize étaient en cuivre. Si des bassins (leğen) et de grandes bassines (mā'ūn) en métal sont mentionnés dans les inventaires après décès ${ }^{29}$, dans les fouilles de la citadelle, ces bassins sont en terre ${ }^{30}$ (pl. 2 : 1). D'un diamètre à l'ouverture compris entre 35 et $63 \mathrm{~cm}$, parfois engobés en rouge ou en noir, parfois glaçurés, ils remplissaient des fonctions relatives à la cuisine, à la lessive ou à l'hygiène corporelle. Les boissons étaient présentées dans des aiguières (ibrīq) et dans des cruches (bātiya) en cuivre étamé. Elles pouvaient être aussi de terre comme en attestent de nombreuses cruches trouvées dans les fouilles (pl. 2 : 2-4). L'eau était mise à rafraîchir dans des barrādiyya et les textes précisent qu'elles étaient fabriquées en terre poreuse de façon à permettre le passage de l'air au travers des parois. De nombreuses gargoulettes à filtre, à pâte grise, au décor peigné, trouvées à la citadelle, remplissaient effectivement cette fonction (pl. 2 : 5-7). Pour la conservation, les inventaires évoquent des pots à beurre en terre vernie dits dabbiyya cependant, en l'absence de précision morphologique supplémentaire, il est difficile d'attribuer cette fonction précise aux rares pots trouvés en fouille. Ces derniers ne sont d'ailleurs pas glaçurés mais peints à l'engobe rouge ${ }^{31}$. Les jarres de resserre, nommées hawābi et marțabān, ne manquent pas dans les niveaux ottomans de la citadelle (pl. $3: 1$ ). Des jarres de taille moyenne, à deux anses, à pâte grise ou rouge, côtoient de très grosses jarres engobées ou partiellement glaçurées. Selon Vital Cuinet - consul de France, secrétaire général de la Dette publique ottomane et membre de la Chambre de commerce française de Constantinople - des jarres étaient produites en 1896 dans les ateliers de Damas, d'Hasbiyya et de Rāšayya al-Faḩhāar ${ }^{32}$. La description qu'il en donne correspond assez bien aux jarres à pâte rose découvertes en grand nombre dans les fouilles et dans les environs de la ville. La nourriture était consommée dans des écuelles en terre dites zabdiyya, un terme qui s'applique peut-être aux nombreuses coupelles à lèvre en crochet, avec une panse hémisphérique, cannelée, et un fond lenticulaire, tournées dans une pâte rouge foncé, très dure avec des inclusions blanches, mises au jour dans les niveaux du XVIII ${ }^{\mathrm{e}}$ siècle ${ }^{33}$ (pl. $3: 2$ ). Gamelles du soldat, elles ont pu être utilisées à l'occasion de distribution de nourriture, sous la forme de yağma ${ }^{34}$. Les mets étaient également présentés dans des plats, tabaq et saḥn, ainsi que dans des bols appelés mašraba qui pouvaient être en cuivre étamé. L'inventaire après décès d'un rôtisseur de Damas précise qu'il servait

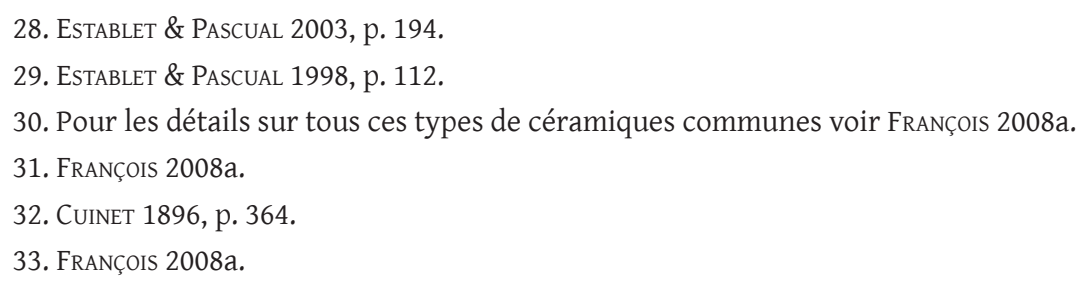

34. Cette ancienne coutume turque consistait à placer les restes d'un repas impérial dans de petits bols disposés dans les rues ou sur les places. Les janissaires étaient les premiers bénéficiaires de ces repas improvisés mais, dans certains cas, c'était à toute la population que ces « offrandes » s'adressaient. C'était un moyen politique de légitimer la présence de la dynastie régnante dans les provinces. ЕмEсEM 2003, p. 100. 
de la viande de mouton dans cinquante plats de type qāšāni ${ }^{35}$. Cette appellation indique qu'il s'agit de céramique fine à pâte siliceuse et glaçure alcaline en rapport avec les productions perses de Kashan d'où le qualificatif est dérivé. Cette vaisselle «à la manière de Kashan » était probablement fabriquée dans les ateliers damascènes. À la citadelle, des plats et des coupes de toutes tailles et de diverses natures se rapportent à cette fonction de service ${ }^{36}$. Les productions syriennes sont représentées par des coupes à pâte argileuse rouge engobées et glaçurées au plomb ou peintes au jaune d'antimoine pour les plus rustiques (pl. $3: 3-4)$. À parts égales, on trouve aussi des plats à pâte siliceuse, ornés d'une grande variété de décors peints sous glaçure alcaline (pl.4:1-2). Cependant, certains résidents de la citadelle ne se contentaient pas de ces simples terres cuites et autres productions locales employées par le plus grand nombre, ils utilisaient aussi une vaisselle importée qui, parfois, était fort coûteuse. Celle, fabriquée dans les ateliers anatoliens d'Iznik à partir du XVI ${ }^{\mathrm{e}}$ siècle, était en effet une production de luxe d'un prix élevé que seuls les Ottomans fortunés pouvaient s'offrir ${ }^{37}$. Des exemplaires de cette production sont présents en petite quantité à la citadelle sous la forme de grands plats à marli chantournés, de jarres, d'aiguières et de coupes profondes (pl.4:3-4). On s'interrogera sur le niveau social des utilisateurs de cette vaisselle précieuse dans un contexte militaire. Les faïences «bleu sur bleu » de Ligurie, au décor de rinceaux finement peints, qui ont remporté un grand succès au Proche-Orient (pl. 4 :5), sont également présentes dans la forteresse. Leur parenté décorative avec les céramiques de type Corne d'Or d'Iznik était peut-être la cause de cette popularité d'autant que leur prix était sans commune mesure avec celui des céramiques anatoliennes. Au XVI ${ }^{\mathrm{e}}$ siècle, ces faïences côtoyaient à la citadelle des majoliques toscanes de Montelupo ainsi que des bols et des coupes de porcelaine chinoise. Plus tard, au XVII ${ }^{\mathrm{e}}$ siècle, certains des habitants installés dans l'enceinte employaient des céramiques Marmorizzate (pl. 4 : 7) et des Graffita Tarda fabriquées dans les ateliers de Pise ainsi que des majoliques de Montelupo, des faïences «bleu sur bleu»d'Albisola en Ligurie et des porcelaines «Bleu et blanc» de Chine (pl.4:6). Au siècle suivant, les importations occidentales étaient encore présentes à la citadelle mais l'approvisionnement était plus varié. Les productions pisanes et ligures étaient respectivement représentées par des faïences à décor spirale verdi et des céramiques « à taches noires », elles rivalisaient avec des faïences des ateliers provençaux de Moustiers et Varages et des faïences de Delft (pl. $5: 1$ ), représentées en très faible quantité dans la fouille ${ }^{38}$. Les fabrications anatoliennes, de grands plats peints réalisés dans les ateliers de Çanakkale dans les Dardanelles (pl. $5: 2$ ), côtoyaient, dans les vaisseliers, des «Bleu et Blanc » de Chine qui étaient toujours en vogue ainsi que des porcelaines imari. Au XIX ${ }^{\mathrm{e}}$ siècle, la vaisselle rustique, en partie fabriquée en

\footnotetext{
35. EstABlet \& PAscuAl 1994, p. 74. En aucun cas il ne s'agit de faïence comme le suggère la traduction car ce terme renvoie à un type de production à pâte argileuse couverte d'une glaçure opacifiée à l'étain qui n'était pas fabriqué dans l'Empire ottoman.

36. FRANÇOIS 2008a.

37. ATASOY \& RABY 1990, p. 23-32.

38. Sur les quantités mises au jour et pour le détail des catégories voir FRANÇOIS 2008a et FRANÇOIS 2009.
} 
Thrace à Didymotique (pl.5:3), a sans doute eu beaucoup de mal à concurrencer les porcelaines et faïences européennes réalisées dans les grandes manufactures de Saxe, de France et d'Angleterre et qui ont inondé le marché de la vaisselle dans tout l'Empire ottoman ${ }^{39}$. Diverses assiettes en provenance des manufactures de Sarreguemines, de CreilMontereau, de Nimy et des grandes usines du Staffordshire constituaient en effet une partie du vaisselier des habitants de la citadelle (pl. 5 : 4-5). Ces importations massives de vaisselle européenne bon marché étaient parfois faites dans le goût oriental. Ainsi en 1885, pour faciliter les affaires commerciales de la France à l'export, les agents consulaires français étaient encouragés à se montrer attentifs aux habitudes et aux besoins des consommateurs ${ }^{40}$. Instruits de leurs goûts, les industries fabriquaient et vendaient des produits céramiques adaptés au marché du Levant, de Roumélie et d'Anatolie. Le consul général de France à Beyrouth, en 1889 et 1890, souhaitait que les grossistes encouragent les fabricants à réaliser des porcelaines spécifiquement pour le marché oriental, prenant en compte les goûts des clients, leur « amour du clinquant » et ceci à des prix raisonnables ${ }^{41}$. Le qualificatif al-māliqi (littéralement les choses brillantes), qu'on trouve à plusieurs reprises cité dans le Dictionnaire des Métiers pour désigner un type de vaisselle vendu à Damas au XIX ${ }^{\mathrm{e}}$ siècle, se rapporte peut-être à ces porcelaines européennes clinquantes ${ }^{42}$. Elles étaient tellement bon marché que les Damascènes ne faisaient plus réparer leur vaisselle chez les muharris ${ }^{43}$. Le volume des importations des pays d'Europe occidentale était tel que les voyageurs européens se plaignaient de la présence, dans les bazars, de cette vaisselle si peu exotique à leurs yeux mais qui, pour les clients orientaux, représentait sans doute une certaine forme de modernité. Cependant les artisans damascènes continuaient à fabriquer des coupes comme ils le faisaient depuis longtemps ${ }^{44}$. En cette fin du XIX ${ }^{e}$ siècle, les clients préféraient les assiettes connues sous le nom d'al-māliqī et cette production de masse ancienne n'était plus vendue qu'aux marchands de beurre, aux vendeurs de fūl et de hummuṣ ainsi qu'aux paysans ${ }^{45}$. Ces coupelles, destinées à contenir des matières grasses comme le beurre et diverses préparations à l'huile d'olive, étaient sans doute glaçurées, l'enduit vitreux imperméabilisant les pâtes poreuses.

Boire le café " plus noyre et amère que la suie détrempée » ${ }^{46}$

À Damas, l'établissement le plus ancien mentionné dans les sources est le café constitué en waqf par Murād Pacha, en 1577, et localisé à proximité de sa mosquée dans le quartier de

\footnotetext{
39. FrançoIs 2008b, p. 81-120; Milwright 2008, p. 121-152.

40. FRANÇOIS 2008b, p. 110.

41. MiLWRight 2008, p. 137.

42. QASIMI, 1960, p. 355-356, 322-323.

43. Ibidem, p. 322-323; Milwright 2008, p. 42, 43.

44. QASIMI 1960, p. 355-356.

45. QASIMI 1960, p. 322-323 traduit dans Milwright 2009, p. 42, 43.

46. Monconys 1973, p. 56.
} 
Suwayqa ${ }^{47}$. Les descriptions des premiers qahwa hāna dans cette ville sont peu nombreuses et font état d'espaces simplement équipés de banquettes, d'un bassin et d'un foyer. À la fin du XVII siècle, d'après H. Maundrell (1665-1701), les grands cafés installés sur les rives du Baradā pouvaient accueillir un grand nombre de clients, de 400 à 500 personnes ${ }^{48}$. Mais les archives des tribunaux, datées du XVII siècle, signalent aussi l'existence d'une trentaine de ces nouveaux lieux de sociabilité masculine à l'intérieur du tissu urbain, dans des secteurs particulièrement fréquentés - dans les souks du centre ou dans les marchés de quartier, souvent à proximité des mosquées et des hammām-s. Des documents juridiques, datés entre 1746 et 1791, révèlent que plusieurs cafés étaient installés dans l'enceinte même de la citadelle, l'un d'entre eux étant localisé à la porte occidentale ${ }^{49}$. Ces débits de café étaient moins vastes que ceux décrits par les voyageurs et résultaient parfois de l'agencement de petites boutiques. Au début du XIx ${ }^{\text {e }}$ siècle, des actes d'achat concernant le matériel des cafés de Damas témoignent d'un aménagement sommaire des lieux indiquant qu'on y trouvait des nattes, des tapis, des tabourets, des divans, des coffres en bois, des lampes à huile suspendues au plafond, des narguilés et quelques tasses ${ }^{50}$.

Dans ces différents établissements, les clients buvaient le café de manière collective ou individuelle. $\mathrm{Au} \mathrm{Xv}$ siècle, dans les cercles soufis, une louche plongée dans un bassin de terre rempli de café passait de l'un à l'autre des mystiques ${ }^{51}$. Cette manière de boire le café en groupe, en faisant circuler un seul récipient, souvent un grand bol de céramique, a été un temps la règle. Une interdiction officielle, établie à Damas en 1543-44, rapporte que le Grand Juge nommé par Istanbul « fait proclamer à l'intention des dukkān al-qahwa que l'on ne doit pas boire en compagnie, avec des chants et en faisant tourner des bols (al-zabādì al-șini $\bar{l}){ }^{52}$. Le recours aux bols communs s'est maintenu dans certaines régions jusqu'à une date fort avancée puisque, en 1822, les Turkmènes, vivant au nord-ouest d'Alep, buvaient leur café dans des tasses «trois fois plus grandes que celles qui sont utilisées communément dans le Levant, aussi larges que des tasses à café anglaises " ${ }^{53}$. Bols et tasses de contenances différentes semblaient coexister dans les débits de café comme l'observait le médecin et botaniste allemand L. Rauwolf (1535-1596) qui voyageait en 1580 d'Alep à Bagdad. Selon lui, les Arabes buvaient le café aussi chaud que possible dans des tasses en porcelaine ou en terre cuite qu'ils faisaient circuler d'un consommateur à l'autre ${ }^{54}$. Le café était aussi servi dans des récipients individuels de très petite taille comme le rapporte d'Ohsson (1740-1807), Chevalier de l'Ordre Royal de Wasa, Secrétaire de Sa Majesté le roi de Suède et chargé d'affaires à la Cour de Constantinople au XVIII ${ }^{\mathrm{e}}$ siècle : « La passion des

\footnotetext{
47. PASCUAL 1995-1996, p. 151-152.

48. MAUNDRELl 1810, p. 173.

49. Des informations qui m'ont été livrées par Brigitte Marino que je remercie.

50. MARINO 1995, p. 279-280.

51. HATTOX 1988, p. 74.

52. PASCUAL 1995-1996, p. 146.

53. BURCKHARDT 1822, p. 20.

54. RAUWOLF 1582, p. 102-103.
} 
Orientaux pour cette liqueur est au-dessus de toute expression (...) Si la visite est longue, on en donne une seconde, même une troisième tasse, à des reprises différentes. Il est vrai que chez eux les tasses sont petites; il en faut trois ou quatre pour en faire une de celles dont on se sert en Europe $"{ }^{55}$. Pour sa part, Ch. White s'étonnait du nombre important, de dix à quinze tasses de café consommées en un jour par une personne, mais nuançait ces chiffres en précisant que toutes ces tasses réunies n'excédaient pas le contenu de deux grandes tasses de thé ${ }^{56}$.

Les inventaires après décès et les inventaires domestiques damascènes étaient consignés par des juges dont les compétences en matière de vaisselle pouvaient être limitées. Les termes qu'ils employaient, sans doute génériques, ne s'appliquaient pas forcément, d'un document à l'autre, à la même réalité. Cependant, ces scribes étaient capables de distinguer les différents types de tasses puisqu'une estimation de leur valeur était indiquée ${ }^{57}$. Dans ces inventaires, les finğān ou tasses à café étaient fréquemment cités mais les termes employés recouvrent une réalité parfois difficile à appréhender ${ }^{58}$. On y distingue par volume décroissant de simples finğān sans qualificatif particulier à 0,10 piastre ; viennent ensuite des tasses 'asali, une épithète mystérieuse qui, évoquant peutêtre le miel, ferait référence à la couleur du matériau ou de la glaçure, leur prix s'élève à 0,07 piastre; des tasses 'ağamī (peut-être de Perse) à 0,09 piastre ; des tasses $\sin \bar{l}^{59}$ à 0,11 piastre; des tasses qualifiées de ğadìd (neuves) à 0,37 piastre; ou encore des tasses gümüşlü, autrement dit en argent, à moins que ce terme ne fasse plutôt référence à un décor de lustre métallique ou n'évoque les sertissages de métal destinés à protéger des chocs les parties sensibles de l'objet. Leur coût s'élève à 3,5 piastre. Quelques finğān sont dits qā̄̌ānī, c'est-à-dire à la manière des productions perses de Kashan, et les tasses făğfūri renvoient aux porcelaines de Chine ${ }^{60}$. Elles coûtent 0,14 piastre. Une pièce, à 0,5 piastre, qualifiée de may est sans doute de couleur bleue tandis que 17 autres sont simplement blanches. Ces documents font état de plusieurs catégories de récipients qui peuvent être identifiées, à partir des descriptions les plus claires, avec des porcelaines de Chine et des céramiques d'Iznik tandis que les qualificatifs de șin̄in, qā̌̄ānī et 'ağamī permettent, sinon de définir l'origine des objets, du moins d'en approcher la nature. Grâce aux artefacts trouvés en fouille, il est possible de donner une réalité matérielle aux finğān mentionnés dans les textes ${ }^{61}$. Comme en écho à ces descriptions, on trouve en effet, à la citadelle de Damas, des

\footnotetext{
55. D’OHSSON 1791, p. 82.
}

56. White, 1845 , p. 280. Des chiffres plus importants sont donnés par Chabrol, certaines personnes, en consommaient jusqu'à trente tasses par jour. CHABROL 1826, p. 56.

57. Establet \& PAsCuAl 1994, p. 87.

58. Le mot tasse (tas), d'origine persane, désigne un récipient à boire tenu d'une seule main mais le terme le plus employé, dans les sources turques et arabes, pour évoquer les tasses est fincan et finğān (du persan finjân).

59. Șinī (de Chine), le mot arabe employé dès le xI siècle et çînî, le mot persan et turc, désignent des terres cuites.

60. Fağfuriyé est un terme turc qui fait référence à l'empereur de Chine et, par association, c'est le nom générique donné aux porcelaines chinoises.

61. Sur l'histoire des tasses à café dans l'Empire ottoman voir FrançoIs 2007a, p. 293-320. 
tasses de diverses sortes ${ }^{62}$. Les porcelaines chinoises «bleu et blanc » étaient parmi les principales catégories de tasses à café. Ces fines coupelles sont peintes au bleu de cobalt, ornées de décors végétaux stylisés - des fleurs de lotus ou de chrysanthèmes, des lingzhi ou champignons sacrés, des fleurons divers - de paysages dans lesquels évoluent parfois des animaux - des oiseaux perchés sur des rochers, des échassiers, des dragons au milieu de nuages ou sortant des flots écumants - ou de quelques pêcheurs (pl. $5: 6$ ). Elles étaient fabriquées dans les ateliers chinois à la fin de l'époque Ming et, pour la plus grande part, à l'époque dite de "Transition » puis sous la dynastie Qing, c'est-à-dire aux XVII et XVIII ${ }^{\mathrm{e}}$ siècles. Dans l'Empire ottoman, les tasses venues de Chine ont été très rapidement adoptées pour servir le café ${ }^{63}$. Choisies parce que la porcelaine, dure, fine et légère, gardait la chaleur du liquide, ces tasses étaient bien adaptées pour la dégustation du café dont la température devait être élevée. Les principaux ateliers ottomans ont repris les formes et parfois les décors de ces petits récipients chinois pour créer des tasses à café qui, cependant, ne sont pas des porcelaines. Ainsi le petit gobelet à panse hémisphérique monté sur une base annulaire est devenu le récipient type pour déguster cette «liqueur toute noire, épaisse et bouillante ». À la citadelle, au XVII siècle, le café se dégustait aussi dans une tasse venue d'Iran (pl. 5 : 7). Réalisée en pâte siliceuse très dure, et ornée, à l'intérieur, d'un bouquet peint au lustre jaune-orangé sur une glaçure stannifère et, à l'extérieur, d'un décor floral avec des grenades peint en bleu de cobalt et lustre jaune d'or et rouge cuivre, cette tasse est peut-être un finğān 'ağamī. C'est le seul exemple perse safavide reconnu sur les sites archéologiques du Proche-Orient. Au XviII ${ }^{\mathrm{e}}$ siècle, la variété des tasses était plus importante, les finğān fağfuri «bleu et blanc » étaient plus nombreux. Ils étaient associés à d'autres tasses en porcelaine dites « café-au-lait » ou Deaf-Leaf Brown, qui se distinguaient par une couverte allant du jaune miel au chocolat employée seule ou parfois associée à des décors peints en bleu. Il est possible que cette glaçure corresponde au qualificatif 'asalì (en rapport avec le miel ?) qu'on rencontre dans les inventaires damascènes. Pour la même époque, les tasses produites dans les ateliers anatoliens de Kütahya apparaissaient en grand nombre ${ }^{64}$ (pl. 5 : 8). Au Bilād al-Šām, ces tasses ont principalement été retrouvées à Antioche, à Hamā, à Acre, dans les citadelles d'Alep et de Jérusalem, à la cathédrale arménienne de St James, au château de Belmont, à Burğ al-Ahmar et à Zírin ${ }^{65}$. Pour leur part, des tasses en porcelaine de Meissen, ont aussi été découvertes à la citadelle. Elles apparaissent occasionnellement dans les fouilles de Tripoli, d'Acre et de Jérusalem ${ }^{66}$ (pl. 5 : 9). Les porcelaines européennes de Meissen et de Vienne, groupées sous le nom générique ottoman de saksunya, étaient très appréciées dans l'ensemble de l'empire dès le deuxième quart du XVIII siècle. En

62. FRANÇOIS 2008.

63. Sur ce point voir FRANçoIs 2007a, p. 303-305.

64. Akalin \& Yilmaz Bilgi 1997, p. 9 ; Carswell \& Dowsett 1972 ; Carswell 1972 ; Soustiel 2000, p. 104-108.

65. WAagé 1948, fig. 87 : 6, 7 ; RIIS \& PoUlsen 1957, p. 131, nº 404 ; Edelstein \& AvisSAR 1997, p. 133, pl. III : 2, 3 ; JohnS 1950, p. 190, pl. LXIII : 8, 9 ; HARPER \& PRINGle et al. 2000, p. 114-116 ; Pringle 1986, p. 157-158, fig. 51, n88-90 ; GREY 1994 , p. 60.

66. Salame-Sarkis 1980, p. 226 ; Edelstein \& Avissar 1997, p. 133, pl. IV : 5a, b ; Carswell \& Dowsett 1972, fig. 32. 
1732, un négociant turc passait commande, à Meissen, de deux mille tasses à café de type fincan aussi nommées Turkencöpgen en Saxe et ce même marchand, en 1734, signait avec la Manufacture un contrat aux termes duquel il s'engageait à acheter tous les ans la même quantité de tasses ${ }^{67}$. Ces pièces étaient exécutées à la commande dans le goût des clients turcs qui fournissaient des modèles et imposaient un type particulier de décors adaptés au goût ottoman. Les tasses de Meissen, des coupelles sans anse, réalisées en porcelaine, sont ornées de décors floraux stylisés souvent peints en polychromie, parfois rehaussés de filets dorés comme à Damas. Enfin, les tasses à café n'étaient pas rares parmi les imitations chinoises des imari japonais qui combinent le bleu et le rouge sous couverte à des rehauts d'or, une production devenue, peu après son introduction au début du XviII ${ }^{e}$ siècle, une marchandise d'exportation très populaire. Les ateliers damascènes n'étaient pas en reste et proposaient à la clientèle locale des petites tasses à pâte siliceuse, peintes au bleu de cobalt ou peintes en polychromie sous une glaçure alcaline incolore. Il est vraisemblable qu'il s'agisse des tasses șin̄i et qaşanī évoquées dans les textes.

\section{S'éclairer}

Pour y voir la nuit ou pour éclairer les courtines, les sombres escaliers et les grandes salles peu ouvertes sur l'extérieur, les soldats et les civils qui vivaient à l'intérieur de l'enceinte avaient sans doute à leur disposition mille et un moyens dont des feux, des torches, des flambeaux, des braseros et des lanternes. Dans un contexte domestique, ils employaient des lampes dont peu d'exemplaires ont été mis au jour. Il ne s'agit plus, comme à l'époque mamelouke, de lampes à huile à coupelle mais de chandeliers et de bougeoirs ${ }^{68}$. Indistinctement cuits en atmosphère oxydante ou réductrice, ces chandeliers reprennent les formes de leurs homologues de métal ${ }^{69}$, c'est-à-dire un socle tronconique ou évasé surmonté d'une collerette de laquelle s'échappe une tige creuse, souvent baguée, terminée en bulbe avec des lèvres éversées (pl. $6: 1-6)$. Simples terres cuites grises ou rouges, elles ne portent aucune trace de glaçure ou d'ornementation peinte. Les bougeoirs de terre de la citadelle étaient sans doute employés au XVII et au XVIII siècles alors que ceux de formes assez proches, tournés dans une pâte rouge, trouvés à Istanbul et dans la forteresse de Belgrade, apparaissaient déjà dans des niveaux du milieu du XVI ${ }^{\mathrm{e}}$ et du début du XVII ${ }^{\mathrm{e}}$ siècle ${ }^{70}$. De la même façon que pour les ustensiles de cuisine, les luminaires, utilisés à la citadelle dans un contexte domestique, étaient peut-être majoritairement faits de métal. Refondus, on ne les retrouve pas en fouilles. L'artisanat du métal à Damas était réputé depuis la fin de

67. SOUSTIEL 1985, p. 348-350.

68. Dans les fouilles de Saraçhane à Istanbul, les lampes à coupelle à fond plat sont également fort rares. Elles réapparaissent, à la fin du XIXe siècle, montées sur une tige ansée. HAYES 1992, p. 297, 372, 387, fig. 130, 145.

69. Les chandeliers en cuivre de même forme, réalisés dès le milieu du Xve siècle, étaient fréquents au milieu du siècle suivant. Ils ont manifestement servi de modèles aux potiers qui s'en sont inspirés pour fabriquer des objets simples comme à Damas ou des pièces de luxe comme les chandeliers très ornés produits dans les ateliers d'Iznik au $\mathrm{XVI}^{\mathrm{e}}$ siècle. Petsopoulos 1982, p. 37, 39, 40.

70. HAYEs 1992, p. 297, 298, 372, 380, fig. 130, 138, 141, 143, 146, 47 ; BiKić 2003, p. 85-86. 
l'époque ayyoubide et le sultan mamelouk al-Ašraf Hुalīl (1290-1293), en 1293, a d'ailleurs passé commande aux ferronniers de la ville de deux cents chandeliers de cuivre, d'or et d'argent ${ }^{71}$. Vers 1860 , les fabricants de lanternes (fānūs) en cuivre étamé étaient encore mentionnés dans le Dictionnaire des Métiers ${ }^{72}$ mais l'arrivée des lampes fonctionnant au kérosène et l'éclairage public des rues ont entraîné peu à peu la disparition des fanārātī.

Fumer du tabac dont "l'abominable odeur empeste la barbe et le turban » ${ }^{73}$

Selon les sources ottomanes, l'habitude de fumer a été introduite au Moyen-Orient par « des infidèles anglais », des marins qui relâchaient dans les ports d'Istanbul ou d'Égypte entre 1599 et 1606. Cette pratique s'est développée très rapidement dans tout l'Empire, même si fumer fut temporairement interdit par le sultan Ahmet $\mathrm{I}^{\text {er }}$ en 1612, prohibée par les autorités religieuses de La Mecque puis punie de mort par le sultan Murad IV, en 1633, à la suite d'incendies qui avaient ravagé un cinquième de la superficie d'Istanbul. Fumer était une véritable affaire d'État puisqu'en 1646, un décret officiel a autorisé la consommation de tabac qui a été légalisée autour de 1720 par une fatwā émise par le mufti de Damas, le šayh 'Abd al-Nābulusī. Dès la première moitié du XVII ${ }^{\mathrm{e}}$ siècle " de nombreux oulémas et grands personnages (...) tombèrent dans le même travers. La racaille des cafés emplissait ces lieux de vapeur bleue au point que l'on ne pouvait se distinguer les uns des autres. Au marché, dans les bazars, leur pipe ne les quittait plus et, s'envoyant mutuellement des bouffées de fumée à la figure et dans les yeux, ils empestaient les rues et les marchés ${ }^{74}$. Au tabac du Nouveau Monde puis à celui de grande qualité cultivé en Syrie, à Lattaquié, dans la région de Saïda et dans la plaine de la Beqaa ${ }^{75}$, s'ajoutaient d'autres substances comme le cannabis ${ }^{76}$. Dans le Tableau général de l'Empire Othoman dressé par d'Ohsson dans la deuxième moitié $\mathrm{du}$ XVIII ${ }^{\mathrm{e}}$ siècle, on lit que :

«Le tabac est d'un usage universel chez les Ottomans. Livrés à cette habitude dès l'enfance, il n'est presque pas de Musulmans qui ne fume six, dix et même vingt pipes par jour. Réunissant le luxe à la volupté, ils mettent autant de recherche dans la beauté des pipes, que dans la qualité du tabac. Les tiges en sont ordinairement de jasmin, de rosier, de noisetier, de cerisier, etc.; elles sont garnies dans leur étendue, en argent ou en or, et toujours terminées par des morceaux d'ambre blanc, d'ambre jaune ou de corail très artistement travaillés. Quelques-uns, parmi les grands, ont encore des pipes à la persane, que l'on appelle Narguilé. Le commun du peuple n'en a que de très-simples, qui sont plus ou moins longues. Les noix qu'ils appellent lulé, et qui servent de fourneaux au tabac, sont d'une terre fine préparée avec un art particulier : il y en a même qui sont dorées. Comme il est de la politesse chez eux d'offrir des pipes à tous ceux qui se présentent dans leurs

\footnotetext{
71. Pour les références voir MiLWRIGHT sous presse.

72. QASIMI 1960, p. 343 traduit par MiLWRIGHT sous presse.

73. PetcheVi 1866, p. 365.

74. Ibidem, p. 365.

75. MURPHEY 1985, p. 205-226.

76. Des traces de hashish ont été repérées dans des pipes, des XVIII et xIXe siècles, trouvées à Jérusalem. SIMPSON 1994,
} p. 14 . 
maisons, on voit dans les antichambres, et même dans les salons des grands, vingt, trente, quarante de ces longues pipes rangées verticalement dans des entailles de tablettes faites pour ces objets. L'usage de fumer est si fréquent, que ceux qui y sont le plus adonnés, ne sortent jamais de leur maison qu'ils n'emportent avec eux leur tabac et leur pipe. Ils mettent le tabac dans un petit sac de satin ou d'étoffe de soie; et la pipe, brisée en deux ou trois morceaux qui se remontent avec des vis d'argent, est renfermée dans un étui de drap attaché à la ceinture sous l'habit ${ }^{77}$.

Comme le décrivait justement d'Ohsson, la pipe ottomane, lüle ou chibouk, était composée de trois parties principales. Le fourneau destiné à contenir le tabac était le plus souvent réalisé en argile ${ }^{78}$. Les premières pipes étaient fabriquées avec des pâtes claires, blanches ou grises, sans doute à la manière des prototypes anglais et hollandais en kaolin. Avant la fin du XVII ${ }^{\mathrm{e}}$ siècle, elles furent remplacées par des argiles rouges dont certaines venaient de Van ou d'Aydın. Ces fourneaux de terre étaient moulés dans des matrices en pierre ou en fer et le décor était obtenu par moulage, estampage, impression à la molette ou au poinçon et par découpage. Ensuite, recouvertes d'une fine couche d'engobe blanc ou rouge, elles étaient souvent polies à l'aide d'un brunissoir ce qui leur donnait un aspect rutilant. Dans la première moitié du XVII ${ }^{e}$ siècle, le tabac étant une marchandise importée coûteuse, les fourneaux étaient de petites tailles. Par la suite, le développement des cultures de tabac en Anatolie et en Méditerranée orientale faisant chuter les prix, le volume des fourneaux a augmenté aussitôt. Au xix siècle, la plupart des fourneaux portaient un sceau qui désignait un individu, une guilde ou un lieu, il consistait parfois en de brèves exhortations religieuses, des emblèmes géométriques ou figurés. Le tuyau (hookah) en bois était fabriqué d'un seul tenant pour les plus courts ou en plusieurs tronçons raccordés par des douilles métalliques pour les plus longs. Les tiges étaient en roseau, en bois de cerisier, de noisetier ou de jasmin. Leurs longueurs variaient de 1 à $4 \mathrm{~m}$ suivant la mode ou le statut de l'utilisateur ${ }^{79}$. Les pipes de luxe et de cérémonie, les plus longues, nécessitaient pour leur transport deux domestiques. L'embout buccal qui s'adaptait sur cette tige pouvait être en corne ou en os, ou fabriqué dans une matière précieuse telle que l'écaille, l'ambre ou le corail. Le tuyau qui se bouchait souvent était changé régulièrement. Le fourneau devait être nettoyé et de nombreux pauvres du Caire s'y employaient d'ailleurs pour gagner leur existence. Selon un voyageur anglais, on entendait à Istanbul, en 1844, des colporteurs " who circulate through the narrow streets; between six and eight a.m. waking tardy risers with shouts of tchibookjee! and tchibookja! ${ }^{80}$.

L'activité de quartiers entiers des grandes villes de l'Empire était entièrement dévolue à la fabrication et la vente de pipes comme le voyageur J. Silk Buckingham (1786-1855) en témoigne. Il rapporte, qu'au début du XIx siècle, cent cinquante fabricants de tuyaux de

77. D'OHSSON 1791, p. 88-90.

78. SiMPSON 1995, p. 17-22.

79. Pour de rares exemples de tuyaux conservés voir RoBINSON 1985, pl. 44 a et b; Gosse 2007, p. 22, 23, 156 et SIMPSON 2009, p. 72.

80. WHITE 1845 , p. 126. 
pipes étaient installés, aux côtés des fabricants de fourneau et d'embouts, à Diyarbak1r ${ }^{81}$. À Istanbul, à Tophane, dans le quartier de Galata, coexistaient plus d'une soixantaine d'ateliers installés dans Lüleci Hendek arasta ${ }^{82}$. D'autres centres importants fabriquaient des pipes en Turquie, à Edirne, Lüleburgaz, Ruscük, Avanos et Iznik, Mardin, Siirt et peut-être Sivas. Mais les ateliers de pipes de Sofia, Beykoz et Burgaz en Bulgarie, ceux de Jiannitsa en Grèce, ceux de Bagdad et Mossoul en Iraq, d'Assiout, Qena, Assoum et Le Caire en Égypte étaient aussi très fameux et exportaient parfois leur production sur de longues distances. Au Bilād al-Šām, des ateliers étaient en activité à Jérusalem, à Jaffa, à Nazareth et à Beyrouth ${ }^{83}$. À Damas aussi des ǵalāyinni proposaient à la clientèle locale des pipes de terre. Les toponymes permettent de localiser cet artisanat dans la circonscription de Mīdān Sultānī dans laquelle se trouvait une Zuqāq al-Ǵalayniyya, autrement dit une rue des fabricants de pipes $^{84}$. Et le Dictionnaire des Métiers confirme que cet artisanat fonctionnait encore au $\mathrm{XIX}^{\mathrm{e}}$ siècle puisqu'une entrée est consacrée aux fabricants de galyūn dont les productions peintes en noir, en rouge ou dorées, étaient les plus recherchées ${ }^{85}$.

Sur les sites archéologiques de Méditerranée orientale et du Proche-Orient, les pipes de terre cuite apparaissent en plus ou moins grand nombre mais, toujours présentes, elles constituent souvent les seules attestations d'une occupation d'époque ottomane ${ }^{86}$. Les premières typologies ont été établies à partir des pipes découvertes à Corinthe (137 objets), à Athènes (107) et à Saraçhane Camii à Istanbul (100) ${ }^{87}$. Ces dernières années, le corpus s'est enrichi grâce au matériel recueilli à Kastellorizo en Égée et à Mytilène (1 300 pipes), à Chypre et en Palestine à Acre, à Belmont (377 pipes), à Burğ al-Ahmar, à Jérusalem (93) et à Tel Yoqne'am ${ }^{88}$. Il faut désormais y ajouter les 481 pipes mises au jour dans les fouilles de la citadelle de Damas qui proviennent principalement d'un casernement (pl. 1, zone 1) et du «bâtiment sud-ouest » (pl. 1, zone 4). Si le décret de Murad IV, interdisant l'usage du tabac, s'adressait surtout aux janissaires qui, semble-t-il, avaient pris de mauvaises habitudes, il n'a été que très momentanément respecté par les militaires de Damas. Ces derniers, en plus du plaisir qu'ils prenaient à fumer, y voyaient peut-être un moyen de rester éveillés pendant les tours de garde. Le chroniqueur I. Petchevi (1574-1650), fort hostile à cette nouvelle pratique, reconnaissait tout de même quelques vertus au tabac: « la seule chose qu'on peut lui concéder est qu'il est utile pour les garde-chiourme des galères, car ceux qui montent la garde sur les bateaux peuvent, dans une certaine mesure, écarter le sommeil par sa consommation» ${ }^{89}$. Un premier ensemble de pipes trouvé dans l'enceinte, réalisé avec

\footnotetext{
81. BUCKINGHAM 1827, p. 380.

82. Le dernier atelier a cessé son activité en 1928. Voir BAKLA 1993.

83. ROGERS 1989, p. 8 ; SIMPSON 2000, p. 171.

84. MARINO 1997, p. 132.

85. QASIMI 1960, p. 330 traduit dans MiLwright 2009, p. 43-44.

86. Pour une liste très complète de ces attestations voir MiLWRIGHT 2000, p. 203-205.

87. RoBINSON 1985, p. 149-203, pl. 33-64 ; HAYES 1980 ; idem 1999, p. 391-395.

88. Wood 1990, p. 8, 9 ; HuMPHREYs 1990, p. 2-9 ; BARAM 1995, p. 299-309.

89. PetcheVi 1866, p. 365.
} 
une pâte claire, presque toujours polie et brillante, date des XVII ${ }^{e}$ et XVIII ${ }^{e}$ siècles. Ces pipes à petit fourneau s'inspirent, dans leurs formes, des pipes anglaises ${ }^{90}$ (pl. $\left.6: 7,8\right)$. Un autre type à pâte claire se caractérise par un anneau percé, sous la douille, qui permet probablement d'attacher le fourneau de terre au tuyau (pl. $6: 9$ ). Les exemplaires de la citadelle, qui datent $\mathrm{du} \mathrm{XVIII}^{\mathrm{e}}$ siècle, peuvent être comparés à d'autres découvertes provenant de sites libanais et syriens avec lesquelles ils entretiennent de frappantes analogies. Il est possible qu'elles soient issues d'une production damascène ${ }^{91}$. Cependant un atelier en activité à la citadelle du Caire, au XviII siècle, fabriquait ce type de chibouk ${ }^{92}$. Les fourneaux ornés de longues feuilles nervurées ou de cyprès imprimés sur la couronne de la douille ou sur le fourneau (pl. 6 : 10) semblent exclusivement caractériser les sites du Bilād al-Šām au XviII siècle tels que Dor, Jérusalem, Tel Jezreel, Safad, Ti'innik, Tel Yoqne'am et le château de Belmont ${ }^{93}$. La collection de Damas complète donc cet échantillonnage et témoigne de la présence de ce type de pipes plus au nord. Le second grand ensemble est constitué de pipes fabriquées, du XVIII ${ }^{\mathrm{e}}$ au début du XIX siècle, avec une pâte rouge, cuisant gris foncé, et recouvertes d'un engobe orange ou rouge, poli et très brillant ${ }^{94}$ (pl. $\left.6: 11-15\right)$. Une grande partie d'entre elles provenait sans doute des ateliers de Tophane à Istanbul dont la production se caractérisait par une surface engobée lie de vin, polie et très brillante. Elles côtoyaient sur les supports de pipes des fumeurs damascènes toutes sortes de chibouk à surface polie rouge ou brune, en forme de lys, à disque, ainsi que des pipes, plus rares, décorées de lignes ondulées réalisées à l'aide d'engobes rouges et beiges (pl. 6 :16). Ces dernières, publiées sous le nom de « swirled fabrics ", ont été trouvées sur le site de Khirbet Hatara au nord de l'Iraq et semblent assez récentes ${ }^{95}$ tandis que deux exemplaires ont été découverts dans le port de la Quarantaine à Pomègues, au large de Marseille, dans un contexte du XviII siècle ${ }^{96}$. L'observation de la taille des douilles permet de cerner la condition sociale des propriétaires des pipes. Les chibouk avec des douilles d'un grand diamètre possédaient vraisemblablement une très longue tige car « la longueur des tuyaux en bois nécessitait pour en assurer la rigidité un diamètre minimum de douille de 10 à $12 \mathrm{~mm} »{ }^{97}$. Compte tenu du diamètre important de la douille de plusieurs fourneaux de grande capacité trouvés à la citadelle, il semble qu'il existait en ce lieu des pipes à longues tiges plutôt d'une utilisation sédentaire, à domicile ou dans les cafés (pl. 6 :17-19). La longueur du tuyau étant proportionnelle au rang social du fumeur, ces pipes témoignaient donc du rang élevé de certains utilisateurs aux XVIII ${ }^{\mathrm{e}}$ et XIX ${ }^{\mathrm{e}}$ siècles. D'ailleurs au XIx $x^{e}$ siècle, les clients des fabricants de pipes damascènes désiraient de longs

90. Robinson 1895, p. 153.

91. Une grande quantité de pipes de ce type a été acquise par la collectionneuse B. van der Lingen à Damas et St. J. Simpson signale aussi leur présence au souk de Damas. VAN DER LINGEN 2000, p. 50-56.

92. PRAdines 2004, fig. 8 f, 9B.

93. Simpson 2000, p. 149.

94. Pour le détail des types voir FrançoIs 2008a.

95. MATNEy 1997, p. 75-76, 85, fig. 4 n¹-3, 13, 23, note 13.

96. Gosse 2007, p. 227.

97. Les pipes avec des diamètres de douilles inférieurs étaient utilisées avec des tuyaux plus courts. Ibidem, p. 160. 
tuyaux ornés qui pouvaient mesurer jusqu'à $2 \mathrm{~m}$ de long et se terminer par un embout d'or ou d'argent. De telles pipes étaient une véritable source de fierté pour leur propriétaire ${ }^{98}$.

E.W. Lane (1801-1876), un voyageur anglais qui s'intéressait aux manières et coutumes des Égyptiens en 1833-1835, précisait que les chibouk étaient plus communément utilisées en hiver, le narghilé étant réservé à l'été ${ }^{99}$. Les fourneaux de narghilés en terre cuite sont rares sur les sites du Bilād al-Šām. Dans les fouilles de la citadelle, bien que ces objets apparaissent dans des contextes non stratifiés, il est possible de les attribuer à la deuxième moitié du xIx siècle sur la base d'analogies établies avec les pipes (pl. $6: 17-19$ ). Les narghilés qui semblent avoir été utilisés plutôt pour la consommation de diverses variétés de tumbak perse que de tabac produit dans l'Empire et mélangés à du hashish témoignent donc d'une certaine prospérité. En 1906, selon C.T. Wilson (1851-?), les narguilés restaient populaires dans les cafés et dans les maisons alors que les pipes étaient remplacées par les cigarettes, sauf chez les Bédouins ${ }^{100}$.

\section{Invoquer les esprits, les anges et les démons}

Dans le monde islamique, du XI ${ }^{\mathrm{e}}$ au XIV ${ }^{\mathrm{e}}$ siècle, des coupes magico-thérapeutiques étaient fabriquées en terre, en alliage cuivreux ou en bronze parfois incrusté d'argent, et étaient en usage chez les puissants comme chez les gens de condition modeste qui s'assuraient ainsi d'une bonne santé et d'une protection contre les calamités et les démons ${ }^{101}$. Des « carrés magiques », des versets coraniques, des lettres isolées, les signes zodiacaux, des symboles et, plus rarement, des figures anthropomorphes et zoomorphes, étaient peints ou incisés sur la surface interne de ces coupelles. La pratique magique consistait à boire un liquide qui, étant entré en contact avec ces mots et ces signes, s'était chargé de leurs pouvoirs. Elle opérait de la même manière que celle qui consistait, pour soigner les malades, à tracer à l'encre des versets coraniques sur des amulettes de papier. Une fois ces dernières placées dans de l'eau, l'encre se diluait et les malades buvaient alors le liquide imprégné du pouvoir magique des mots. Cet usage est passé du papier au métal. Les inscriptions gravées, ayant l'avantage d'être indélébiles, servaient à de nombreuses reprises.

À l'époque ottomane, des plats de porcelaines chinoises spécialement réalisés pour une clientèle musulmane attestaient une foi maintenue dans les pouvoirs magiques des mots et des chiffres ${ }^{102}$. À Topkapı Sarayı, le sultan et son entourage utilisaient ces porcelaines ainsi que d'autres poteries dont les vertus thérapeutiques étaient liées à la matière même dont elles étaient fabriquées. Ainsi les sources rapportent que, Mehmed II (1432-1481), inquiet pour sa santé, a ordonné que lui soient livrées de grandes tasses et des chopes

\footnotetext{
98. QASIMI 1960, p. 330 traduit dans Milwright 2009, p. 44.

99. LANE 1860, p. 185.

100. WiLSON 1906, p. 127 ; QASIMI 1960, p. 330.

101. Sur les coupes magico-thérapeuthiques d'époques ayyoubide, mamelouke et ottomane et la bibliographie afférente se reporter à FRANçoIs 2007b, p. 35-46.

102. FrançoIs 2007b, p. 39-40 ; Chinese 2001, p. 76-77, pl. 21, 85, pl. 28 ; CARswell, 1995, p. 84, nº 90 ; Odyssée 2004, p. $237, \mathrm{n}^{\circ} 192$, p. $238, \mathrm{n}^{\circ} 194$.
} 
en tin-i mahtum, persuadé qu'il était que ces plats se briseraient au contact de poisons ${ }^{103}$. Il s'agissait de grandes tasses et de chopes, tournées dans une argile blanche extraite de gisements fameux exploités depuis l'Antiquité sur l'île de Lemnos, et estampées d'un sceau attestant l'origine de l'argile. La vertu curative de cette terre était encore reconnue à l'époque ottomane et, si son utilisation pharmacologique et médicale suivait les pratiques antiques, elle avait désormais des vertus prophylactiques. Dans l'Empire ottoman, l'usage de talismans thérapeutiques et apotropaïques réalisés en métal précieux ou non et le port de chemises talismaniques témoignaient d'un monde dans lequel les forces occultes occupaient une grande place dans toutes les couches de la société ${ }^{104}$. Une coupelle, mise au jour dans les fouilles de la citadelle, s'inscrit sans doute dans cette tradition.

Il ne s'agit pas, à Damas, d'une porcelaine mais d'une simple terre cuite à pâte argileuse rouge. Cette écuelle ne se distingue de ses nombreux homologues, présents en quantité dans la fouille, que par son « décor » tracé en noir sur les surfaces internes et externes de la panse (pl. 7). A l'intérieur, trois personnages sont grossièrement dessinés en représentation frontale. Le premier, un homme aux bras levés, est vêtu d'une robe ornée de divers signes et d'une cape à plumes (?), ses cheveux semblent hérissés sur son crâne. Trois lettres d'un alphabet à lunettes le séparent d'un deuxième personnage, plus statique et plus sobre dans sa mise, peut-être une femme. Trois nouvelles lettres, distinctes des précédentes, l'isolent d'une troisième personne, vraisemblablement couchée au pied de la première figure, et dont ne subsistent que le bas de la robe et une jambe. Sur la surface externe de la panse, trois registres d'un alphabet à lunettes, dont il manque quelques lettres, sont superposés. Sur les coupes magiques, les représentations figurées sont rares et caractérisent seulement les productions les plus anciennes ${ }^{105}$. Certaines représentations de couples, observées sur des coupes d'influence arménienne et chi'ite du début du xx siècle, sont identifiées comme des « love potion vessels » qui garantissaient le succès du mariage ${ }^{106}$. Cependant, sur l'écuelle de Damas, en plus d'un couple séparé par des lettres, un troisième personnage couché ne trouverait sans doute pas sa place sur un objet favorisant l'attachement conjugal. À la différence des coupelles métalliques tardives iraniennes, mogholes ou égyptiennes ${ }^{107}$, il n'y a, sur l'exemplaire de Damas, aucun « carré magique » ni aucun verset coranique. L'alphabet choisi consiste en caractères à lunettes déjà extrêmement répandus à l'époque islamique moyenne et dont on retrouve la trace sur les talismans métalliques ottomans ${ }^{108}$. Ces caractères mystérieux et souvent incompréhensibles, employés dans la magie musulmane, étaient, selon les auteurs anciens, des noms divins, écrits sous la forme de lignes courbes

103. FRANÇOIS 2007b, p. 39-40.

104. BERK 2004, p. 18-27 ; ŞAIK GÖKYAY 2004, p. 46-60 ; FRANÇOIS $2007 \mathrm{~b}$.

105. FRANÇOIS $2007 \mathrm{~b}$.

106. Ces informations m'ont été livrées par Anne Regourd (chercheur associé au CNRS-Centre d'Études religieuses du Livre, Paris et au GREMMO, Lyon) à qui j'adresse tous mes remerciements.

107. Pour des exemples de ces coupes voir FrançoIs 2007b, p. 35-46.

108. BERK 2004, p. 24-25. 
se terminant en boucles, venus directement aux musulmans de la magie juive ${ }^{109}$. Cette graphie indéchiffrable et inintelligible pour le commun possédait une vertu spéciale en raison du caractère magique de ce qui était mystérieux. Sur l'écuelle de la citadelle, l'encre noire (?) utilisée pour tracer le décor ne s'efface pas au contact d'un chiffon détrempé. Pour des raisons évidentes de conservation, il n'a pas été possible de verser un liquide dans la coupe pour s'assurer que les images et les lettres se diluaient bien à son contact.

Des pratiques en rapport avec les djinns et les anges permettent peut-être de préciser la fonction de cette écuelle ${ }^{110}$. Dans la magie illicite, les magiciens et les sorciers adressaient leurs suppliques directement aux djinns et aux démons pour se débarrasser des šayātīn souvent à l'origine de maladies épidémiques. Certains procédés s'apparentaient à de véritables exorcismes. L'Égyptien al-Suyuṭī (1445-1505) recommandait de «frapper, flageller les génies pour les forcer à partir » ${ }^{111}$. Pour cela, il était nécessaire de tracer « une figure de diable dans un plat, sur un sac à provision, ou même par terre et frapper cet objet avec une baguette de grenadier ou de cognassier sur laquelle vous avez écrit une série de noms magiques et de passages du Coran; les djinns crieront grâce, alors arrêtez-vous et demandez-leur ce qu'il vous plaira ${ }^{112}$. La coupe de Damas, qui allie personnages étranges et inscriptions, correspond assez bien à cette description d'usage. Une autre piste confirme le lien possible entre cette écuelle et le monde des esprits. Il s'agit d'un texte rédigé par le poète et polygraphe turc Firdevsî-i Rumî (1453-1517) ${ }^{113}$. Son Davetnâme, écrit en 1487, traite des sciences occultes ${ }^{114}$. Ce manuscrit est connu sous la forme d'une copie réalisée en 1702-1703 et richement illustrée de cent quarante images représentant les signes du Zodiaque, les planètes, les constellations, les anges et les démons - des vignettes, qui par leur style, sont plus proches des illustrations populaires que des miniatures ottomanes. La première partie de cette oeuvre est consacrée au monde des esprits. Firdevsî-i Rumî y explique pourquoi Dieu a créé les esprits, quelles sont les différences entre eux et ce que chacun représente. Il y est aussi question des anges, pourquoi ils ont été créés, quels en sont les différents types, quelles sont leurs formes et leurs fonctions. Les moyens pour les invoquer sont détaillés. Car une personne qui désirait faire appel à ces êtres surnaturels et les faire obéir à ses ordres devait respecter toute une série de recommandations. Il lui fallait notamment connaître leurs noms, leurs formes, leurs sceaux, leurs formules talismaniques, la période et les lieux les plus propices pour les solliciter. Pour invoquer ces êtres de l'au-delà, il convenait d'écrire certaines formules à l'aide de musc, de safran, d'eau de rose, de camphre, d'eau de pluie d'avril, d'eau salée, de jus de concombre et d'oignons

109. IBN WAHŠIYYA 1977, p. 150, 151, 158, 164-167, 172 ; DOUTTÉ 1909, p. 158.

110. FAHD 1971, p. 155-214.

111. Ğalāl al-Dīn al-Suyuțī, aussi connu sous le nom d'Ibn al-Kutub, auteur égyptien, grand polygraphe de la littérature arabe, cité dans DoutTé 1909, p. 222.

112. DoutTÉ 1909, p. 222.

113. Connu aussi sous le nom de Firdevsî-i Tavil, et de son vrai nom Şerefeddin Musa, il est l'auteur de dix-sept ouvrages, dont le principal est le Süleymânnâm-i Kebir ou Livre de Salomon, une oeuvre encyclopédique dans laquelle se trouve consigné tout le savoir de son temps dans maintes disciplines.

114. BÜYÜKKARCI 2004, p. 28-45. 
blancs, d'huile de lin ou d'olive, de peau d'oignon, de vinaigre, de sucre ou de vert de gris. Ces formules étaient tracées sur divers supports : sur du papier blanc ou jaune de même nature que celui fabriqué en Chine, à Samarkand ou à Bagdad, sur des morceaux d'un vieux cercueil ou d'un linceul, sur de la soie blanche ou à motifs, sur de la cire, sur des plaques de fer, de cuivre ou d'étain, sur du bois odorant ou non, sur du verre et sur de la poterie. Si ces invocations avaient pour but premier de protéger des maladies et de se garantir des grandes peurs, cette magie avait bien d'autres fins comme obtenir la protection des fées et des démons, défendre sa maison des sortilèges et contraindre les démons à accomplir certaines tâches. Les habitations, les animaux domestiques, les jardins et les cultures étaient ainsi défendus. Par ce biais, on espérait augmenter le rendement de ses récoltes, aider au développement de ses affaires commerciales. Ces esprits étaient sollicités pour obtenir la pluie, contrôler l'eau, trouver des sources, alimenter des fontaines ou des puits, se préserver de la fureur des flots et éviter les naufrages. Les applications de ces rites magiques embrassaient tout le domaine de l'utile : pour obtenir l'amour d'un seul ou de tous et renforcer sa puissance sexuelle; pour favoriser l'apprentissage du savoir et des connaissances; pour se protéger des calomnies et lutter contre l'intrigue; pour s'assurer la faveur des puissants ; dans la guerre, pour se procurer la victoire, pour bien tirer, pour se rendre invulnérable ou pour obtenir la délivrance d'un prisonnier; pour voyager en sécurité ; pour l'ouverture des serrures ou le bris des chaînes. Dans tous les cas, il était nécessaire de posséder le nom des anges et des démons et les formules mais aussi de connaitre l'astrologie afin de pouvoir les invoquer lors des meilleures conjonctions astrales. Et leur représentation, selon Firdevsî-i Tavil, obéissait à ces divers éléments. Le manuscrit $\mathrm{du}$ xVIII ${ }^{e}$ siècle livre de nombreux dessins d'êtres étranges, à tête diabolique et à quatre bras, à trois têtes et six bras, à double tête d'homme et de bœuf qui sont en fait les créations d'anges sollicités suivant des conjonctures zodiacales précises. Car si l'incantation était un rite oral, cette énonciation au lieu d'être faite par la parole pouvait aussi être écrite ou exprimée par une image ${ }^{115}$. Il était alors nécessaire de personnifier et de créer la figure du démon ou de l'ange lui-même ce que confirme E. Doutté « il y a toute une série de rites où il semble que l'invocateur créé le génie dont il va se servir » ${ }^{116}$. Aussi les personnages bizarres de la coupe de Damas pouvaient-ils être considérés comme des personnifications d'anges accompagnées de leurs noms tracés à l'aide de lettres magiques dont l'invocation répondait à de nombreuses sollicitations bien terrestres. Les contextes de découvertes sans être très indicatifs permettent toutefois de replacer l'objet dans un milieu d'utilisation assez large. Dans la citadelle qui n'était plus une forteresse fermée, hommes et femmes, civils et janissaires, avaient sans nul doute bien des raisons d'invoquer les djinns et les anges. Cette coupe de terre mystérieuse les y a peut-être aidés ${ }^{117}$.

115. DouTTÉ 1909, p. 143.

116. Ibidem, p. 117-118.

117. La présence d'un bol magique dans la forteresse n'est d'ailleurs pas une nouveauté en ce lieu puisque sur une coupe magique mamelouke de la collection de l'abbé de Tersan une inscription thérapeutique précise que l'objet « ...was copied from [an exemple in] the celebrated Treasury of the Fortress of Damascus the Protected [city] ». ITTIG 1982, p. 82. 
Si l'exploitation des documents écrits fournit de précieuses indications sur les ustensiles de terre et de métal utilisés à l'époque ottomane, il est exceptionnel qu'une correspondance soit établie avec les objets conservés jusqu'à nos jourss ${ }^{118}$. Grâce aux céramiques trouvées en fouille à la citadelle de Damas, il est possible de donner une réalité matérielle aux objets évoqués dans les textes. L'étude croisée des contextes, tels qu'ils sont livrés par les découvertes archéologiques et par les documents d'archives, permet d'esquisser le cadre dans lequel étaient utilisés jarres, plats, lampes, tasses à café et pipes et, par là même, de mieux connaître quelques aspects de la vie quotidienne dans cette ville-garnison entre le $\mathrm{XvI}^{\mathrm{e}}$ et le XIX ${ }^{\mathrm{e}}$ siècle.

118. Dans ce contexte, la publication remarquable de N. Atasoy et J. Raby en 1990 fait figure d'exception puisque textes et objets ont été associés afin de livrer une image très complète de la production et de l'utilisation de la vaisselle de luxe d'Iznik. ATASOY \& RABY 1990. 


\section{Bibliographie}

Akalin, Şebnem \& YiLmaz BilgI, Hülya, 1997 : Delights of Kütahya, Kütahya Tiles and Pottery in the Suna \& Inan Kiraç Collection, Istanbul.

ARNAUd, Jean-Luc, 2006 : Damas. Urbanisme et architecture 1860-1925, Arles, Actes Sud.

D’Arvieux, Laurent, 1982: «Mémoires par Laurent d'Arvieux, in Antoine Abdelnour (éd.), Voyageurs d'Orient II, Beyrouth, Dar Lahad Khater.

ATASOY, Nurhan, \& RABY, Julian, 1990 : Iznik, La poterie en Turquie ottomane. Paris, éd. du Chêne.

BAKLA, Erdinç, 1993 : Tophane Lüleciliği. The Pipe-Making Industry of Tophane, Istanbul, Antik A.S., Dişbank.

BARAM, Uzi, 1995 : «Notes on the Preliminary Typologies of Production and Chronology for the Clay Tobacco Pipes of Cyprus », Report of the Department of Antiquities, Cyprus, p. 299-309.

BERK, Süleyman, 2004 : «Ottoman Talismanic Seals », in Magic in Art, Art and Culture Magazine 12, p. 18-27.

BERTHIER, Sophie \& AL-AJJI, Edmond, (dir.), 2002 : Études et travaux à la citadelle de Damas. 2000-2001 : un premier bilan, Bulletin diétudes orientales 53-54 (Supplément).

Biкić, Vesna, 2003 : Gradska keramika Beograda (16-17.vek) - Belgrade Ceramics in the $16^{\text {th }}-17^{\text {th }}$ Century, Belgrade.

BucKinghAm, James S., 1827 : Travels in Mesopotamia. Including a Journey from Aleppo to Baghdad, by the Route of Beer, Orfa, Diarbekr, Mardin and Mosoul, and other Ancient Cities, vol. I, Londres.

BURCKHARDT, Jean Louis, 1822 : Travels in Syria and the Holy Land, Londres [rééd. 1983].

BÜYÜKKARCI, Fatma, 2004 : « The World of Spirits in Firdevsî-i Tavil's Davetnâme Book of Magic » in Magic in Art, Art and Culture Magazine 12, p. 28-45.

CARSwELL, John, 1972 : Kütahya Tiles and Pottery from the Armenian Cathedral of St. James, vol. II, Jérusalem.

CARSwell, John, 1995 : Chinese Ceramics in the Sadberk Hanim Museum, Istanbul.

CARswell, John \& DowseTt, Charles J. F., 1972 : Kütahya Tiles and Pottery from the Armenian Cathedral of St. James, vol. I., Jérusalem,

CHABRoL, Gaspard de 1826 : Essai sur les moeurs des habitants modernes de l'Égypte, Description de l'Égypte, État moderne, vol. XVIII, 1, Paris, Panckouke.

Chevedden, Paul E., 1986 : The Citadel of Damascus, PhD University of California, Los Angeles.

CHINESE, 2001 : Chinese Treasures in Istanbul, Istanbul.

CuINET, Vital, 1896: Syrie, Liban et Palestine: géographie administrative, statistique, descriptive et raisonnée, Paris.

DoutTÉ, Edmond 1909 rééd. 1994 : Magie et religion dans l'Afrique du Nord, Alger, éd. Ledoux

Edelstein, Gershon \& Avissar, Miriam, 1997 : «A Sounding in Old Acre », 'Atiqot 31, p. 129-136.

EMECEM, Feridun M., 2003 : « The Şehzade's Kitchen and its Expenditures an Account Book from Şehzade Mehmed's Palace in Manisa, 1594-1595 », in Suraiya Faroohi \& Christoph K. Neumann (eds.), The Illuminated Table, the Prosperous House, Würzburg, p. 89-126.

Establet, Colette, 1994 : « Les intérieurs damascains au début du xviII ${ }^{e}$ siècle... sous bénéfice d'inventaire », in Daniel PANZAC (dir.), Les villes dans l'Empire ottoman : activités et sociétés, II, Paris, CNRS Éditions, p. 15-46. 
Establet, Colette \& Pascual, Jean-Paul, 1994: Familles et fortunes à Damas. 450 foyers damascains en 1700. Damas.

Establet, Colette \& PAscual, Jean-Paul, 1998 : Ultime voyage pour La Mecque. Les inventaires après décès de pèlerins morts à Damas vers 1700. Damas.

Establet, Colette \& Pascual, Jean-Paul, 2003 : «Cups, Plates, and Kitchenware in Late Seventeenthand Early Eighteenth Century Damascus », in Suraiya FARoQHi \& Christoph K. NeumanN (eds.), The Illuminated Table, the Prosperous House, Würzburg (Beiruter Texte und Studien 73), p. 185-198.

FAHD, Toufic, 1971 : «Anges, démons et djinns en Islam », in Génies, anges et démons (Sources orientales 8), p. 155-214.

FrançoIs, Véronique, 2007a : «Éléments pour une biographie des tasses à café dans l'Empire ottoman », Turcica 39, p. 293-320.

FRANçoIs, Véronique, 2007b: «Invoquer les esprits à la Citadelle de Damas ou de l'usage d'une coupe magique ottomane », Levant 39, p. 35-46.

FrançoIs, Véronique, 2008a : Céramiques de la citadelle de Damas. Époques mamelouke et ottomane, CD, Aix-enProvence.

FRANçoIs, Véronique, 2008b : « Jarres, terrailles, faïences et porcelaines dans l'Empire ottoman $\left(\mathrm{XVIII}^{\mathrm{e}}\right.$-XIX ${ }^{\mathrm{e}}$ siècles) », Turcica 40, p. 81-120.

FrançoIs, Véronique, 2009 : «Céramiques d'époque ottomane à la Citadelle de Damas : des découvertes archéologiques nouvelles au Bilâd al-Châm », Al-Rāfidān 30, p. 53-66.

Gosse, Philippe, 2007 : Les pipes de la quarantaine, fouilles du port antique de Pomègues (Marseille), in Peter DAVEY (éd.), The Archaeology of the Clay Tobacco Pipe, Oxford Archeopress (BAR-IS 1590).

GREY, Anthony D., 1994 : « The Pottery of the Later Periods from Tel Jezreel: an Interim Report », Levant 26, p. 51-62.

HARPER, Richard P., PRINGLE, Denys, et al., 2000 : Belmont Castle: the Excavation of a Crusader Stronghold in the Kingdom of Jerusalem, Londres, The British Academy (British Academy Monographs in Archaeology, $\left.n^{\circ} 10\right)$.

Hatтox, Ralph S., 1988: Coffee and Coffehouse, The Origins of a Social Beverage in the Medieval Near East, University of Washington Press.

HAYes, J.W., 1980 : « Turkish Clay Pipes: A Provisional Typology », in Peter Davey (ed.), The Archaeology of the Clay Tobacco Pipe n 4, BAR-IS 92, p. 3-10.

HAYES, John W., 1992 : Excavations at Saraçhane in Istanbul, volume II : the Pottery, Princeton.

Hitzel, Frédéric, 2007 : Artisans et commerçants du Grand Turc, Paris, Realia-Les Belles Lettres.

HUMPHREY, John W., 1990 : « The Turkish Clay Smoking Pipes of Mytilene », Society for Clay Pipes Research 26, p. 2-9.

Ibn WAHŠIYYA, 1977 : «La connaissance longuement désirée des alphabets occultes enfin dévoilée », in Sylvain MATTON : La magie arabe traditionnelle, Paris, p. 150-172.

INALCIK, Halil, 1991 : « Matbakh », Encyclopédie de l'Islam, 2e édition, Leiden, Brill, p. 800.

INALCIK, Halil \& QUARTAERT, Donald, 1994 : An Economic and Social History of the Ottoman Empire 1300-1914. Cambridge, Cambridge University Press.

IтTIG, Annette, 1982 : «A Talismanic Bowl », Annales islamologiques 18, p. 79-94.

JoHns, Cedric, N., 1950 : « The Citadel Jerusalem. A Summary Work since 1934 », Quarterly of the Department of Antiquities in Palestine 15, p. 121-190. 
LANE, Edward W., 1860 : An Accounts of the Manners and Customs of the Modern Egyptians, Londres.

LORTET, Dr., 1884 : La Syrie d'aujourd'hui. Voyages dans la Phénicie, le Liban et la Judée (1875-1880), Paris.

MantRan, Robert, 1962 : Istanbul au XVII siècle, Paris.

MARINo, Brigitte, 1995 : «Cafés et cafetiers de Damas aux XvIII et xIx siècles », Revue du monde musulman et de la Méditerranée 75-76, p. 275-294.

MARINo, Brigitte, 1997 : Le faubourg du Mĩdān à Damas à l'époque ottomane. Espace urbain, Société et Habitat (1742-1830), Damas.

MAtney, T., 1997 : « Rapporto di scavo a Khirbet Hatara Saddam Dam, Eski Mossul, Iraq, n 18 », Mesopotamia XXXII, p. 7-86.

MAUNDRELL, H.,1810 : A Journey from Aleppo to Jerusalem at Easter 1697, Londres.

MiLwright, Marcus, 2000 : «Pottery of Bilad al-Sham in the Ottoman Period: a Review of the Published Archaeological Evidence », Levant 32, p. 189-208.

Milwright, Marcus, 2008 : «Imported Pottery in Ottoman Bilad al-Sham », Turcica 40, p. 121-152.

MiLWRIGHT, Marcus, 2009 : «Written Sources and the Study of Pottery in Bilad al-Sham », Al-Rāfidān 30, p. 37-52.

Milwright, Marcus, 2012 : "Metalworking in Damascus at the End of the Ottoman Period: An Analysis of the Qāmūs al-șinā'āt al-Shāmiyya", in Venetia PORTER \& Mariam ROSSER-OWEn (dir.), Metalwork and Material Culture in the Islamic World. Art, craft and text, London \& New York, I.B. Tauris, p. 265-280.

Monconys, Bruno de, 1973 : Voyage en Egypte, Le Caire, IFAO.

Murphey, R., 1985 : "Tobacco Cultivation in Northern Syria and Conditions of its Marketing and Distribution in the Late Eighteenth Century », Turcica 17, p. 205-226.

D’OHsson, M., 1791 : Tableau général de l'Empire Othoman, 7 vol., Paris.

Odyssée, 2004 : L'Odyssée de la porcelaine chinoise. Collections du musée national de céramique, Sèvres et du musée national Adrien Bouché, Limoges, Paris.

Pascual, Jean-Paul, 1983 : Damas à la fin du xvie siècle, Damas.

PASCUAL, Jean-Paul, 1995-1996 : «Café et cafés à Damas : contribution à la chronologie de leur diffusion au XVI ${ }^{e}$ siècle », Berytus 42, p. 151-152.

Petchevi, I., 1866 : Peçcevi Tarihi, Constantinople, I.

Petsopoulos, Y. (dir.), 1982 : Tulips, Arabesques \& Turbans. Decorative Arts from the Ottoman Empire, Londres, Alexandria Press.

PocockE, R., 1743-1745 : A Description of the East and Some other Countries, Vol. II, Book the Second of Asia Minor, chap. XXI, Londres.

PocockE, R., 1745 : Description of the East and Some Other Countries, Vol. II, Part I, Observations on Palestine and Holy Lands, Syria, Mesopotamia, Cyprus and Candia, BOWYER, W. (ed.), Londres.

PRADINES, Stéphane, 2004 : « Note préliminaire sur un atelier de pipes ottomanes à l'est du Caire », Cahiers de la céramique égyptienne 7, p. 281- 289.

PRINGLE, Denys, 1986 : The Red Tower (al-Burj al-Ahmar).Settlement in the Plain of Sharon at Time of the Crusaders and Mamluks A.D. 1099-1516, Londres.

QĀsIMĪ, Muhammad Sa id (AL-), AL-QĀsimī, Ǧamāl al-Dīn (AL-), 'AẒM, Halīl (AL-), 1960 : Dictionnaire des métiers damascains, ed. Zāfir al-Qāsimī, 2 vols., Paris \& Le Haye, Mouton and Co (Le Monde d'Outre-Mer passé et présent. Deuxième série. Documents III). 
RAFEQ, Abdelkarim, 1981: «Economic Relations between Damascus and the Dependant Countryside, 1743-71 », in Abraham L. Udovitch (ed.), The Islamic Middle East, 700-1900: Studies in Economic and Social History, Princeton New Jersey, p. 653-685.

RAFEQ, Abdlelkarim, 1993 : « Le mahmal en route pour La Mecque », in Damas : Miroir brisé d'un Orient arabe, Paris, Autrement, p. 49-57.

RAuWoLf, Leonhard, 1582: Aigentliche Beschreibung der Raisse in die Morgenlander, Laugingen, Leonart Reinmichel, p. 102-103.

RAYMOND, André, 1989 : «Les provinces arabes (xve-XVIII ${ }^{e}$ siècles) », in Robert MANTRAN (dir.), Histoire de l'Empire Ottoman, Paris, p. 341-420.

RiIs, Poul J., PoulsEn, Vagn, 1957 : Hama. Fouilles et recherches 1931-1938. Les verreries et poteries médiévales, Copenhague.

Robinson, R.C.W., 1985 : « Tobacco Pipes of Corinth and of the Athenian Agora », Hesperia 54/2, p. 149-203.

Roşu, Arion, 1992: «Une coupe magique d'époque moghole au musée Guimet », Journal Asiatique 280, p. 251-277.

ŞAIK GÖKYAY, Orhan, 2004 : « Talismanic Shirts », Magic in Art, Art and Culture Magazine 12, p. 46-60.

SALAME-SARKIS, Hassan, 1980 : Contribution à l'histoire de Tripoliet de sa région à l'époque des Croisades: problèmes d'histoire, d'architecture et de céramique, Paris, Paul Geuthner (BAH 106)

SAMANCI, Özge, 2009 : La culture culinaire d'Istanbul au 19e siècle : l'alimentation, les techniques culinaires et les manières de table, thèse de doctorat EHESS, Paris.

Simpson, St. J., 1994 : « Near Eastern Pipe News », Society for Clay Pipes Research 44, p. 14.

SimPson, St. J., 1995 : « An Ordeal with a Pipe: Changing Attitudes to smoking in the Near East during the 17th-18th Centuries » Society for Clay Pipes Research 47, p. 17-22.

Simpson, St. J., 2000 : « The Clay Pipes », in Richard P. HARPer, Denys Pringle, et al., Belmont Castle: the Excavation of a Crusader Stronghold in the Kingdom of Jerusalem, Londres, The British Academy (British Academy Monographs in Archaeology 10), p. 147-171.

Simpson, St. J., 2009 : « The Archaeology of the Clay Pipe in the Near East », Al-Rāfidān 30, p. 67-75.

Soustiel, Jean, 1985 : La céramique islamique. Le guide du connaisseur, Fribourg, Office du Livre.

Soustiel, Laure, 2000 : Splendeurs de la céramique ottomane du XVIe au XIXe siècle, Istanbul.

TOURNEFoRT, Joseph Pitton de, 1982 : Voyage d’un botaniste, 2 vol., éd. Stéphane Yerasimos, Paris, Maspero.

VAN DER LINGEN, B. , 2000: « Ottoman Clay Tobacco Pipes with Loops from Syria and Lebanon », Society for Clay Pipes Research 57, p. 50-56.

WAAGÉ, Frederick O., 1948 : Antioch-on-the Orontes. IV Ceramics and Islamic Coins, Princeton.

WHITE, Charles, 1845 : Three Years in Constantinople; or, Domestic Manners of the Turks in 1844, 3 vol., Londres. WiLson, Charles T., 1906 : Peasant Life in the Holy Land, Londres.

WooD, J., 1990 : « Pipes from the Island of Kastelloriso », Society for Clay Pipes Research 25, p. 8-9.

ZIADEH, Nicolas, 1982 : Damascus under the Mamlūks, Norman, University of Oklahoma Press. 

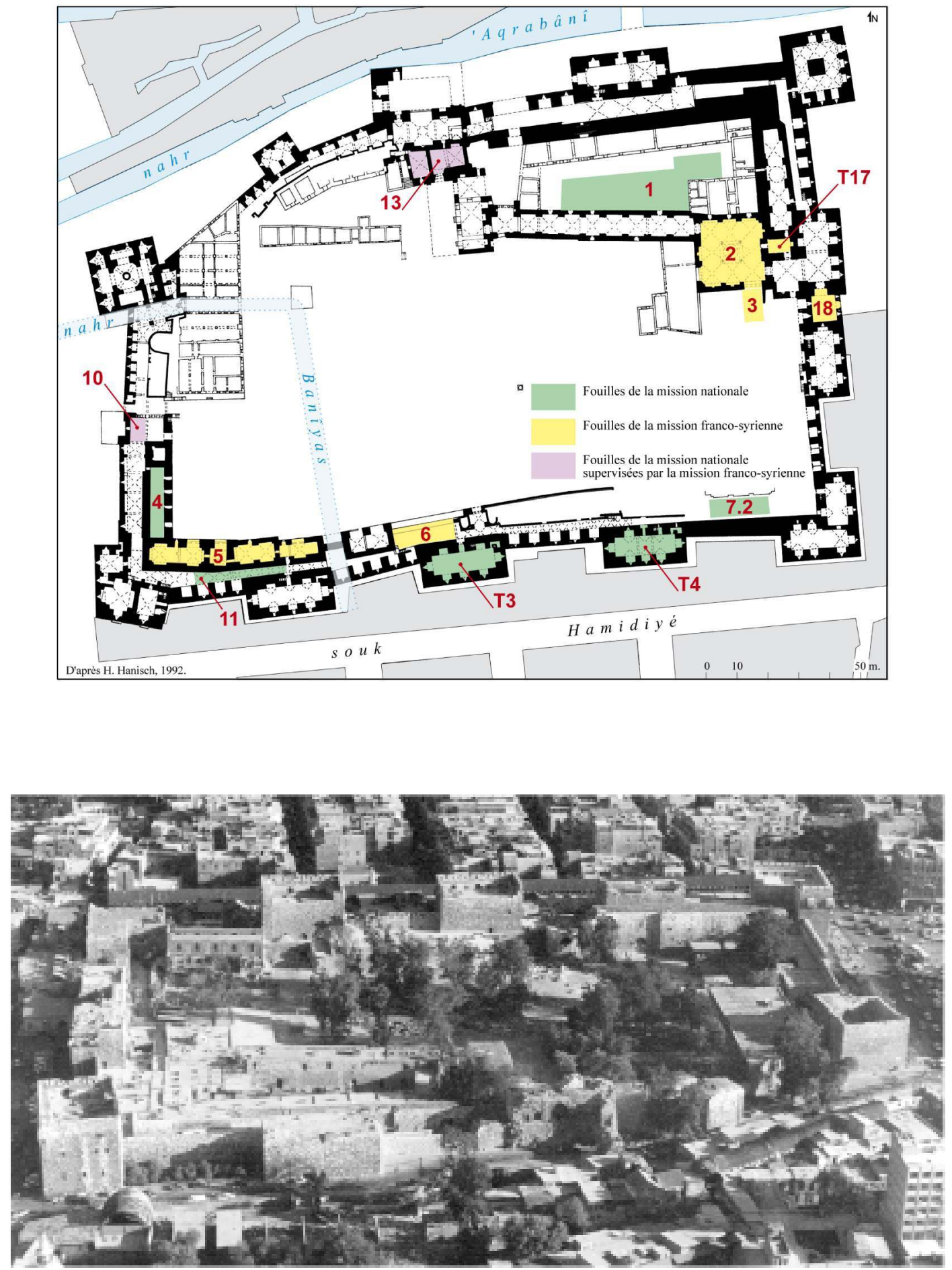

Pl. 1 - Plan et situation des secteurs fouillés et vue aérienne de la citadelle. 

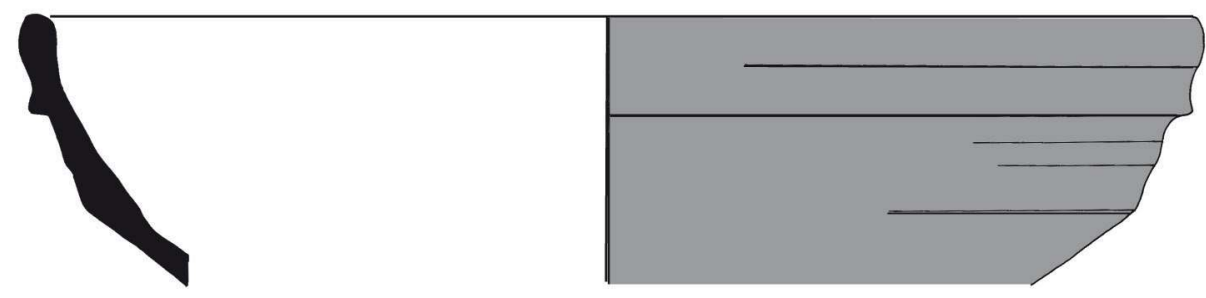

1

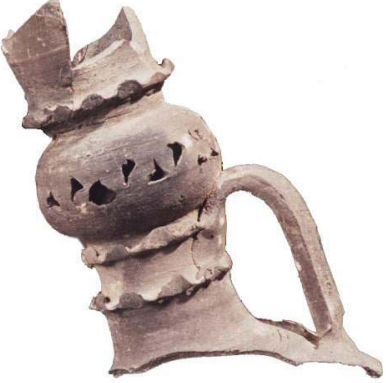

2

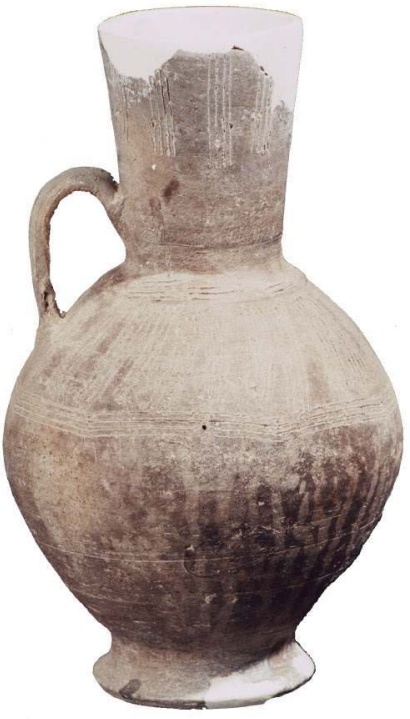

5
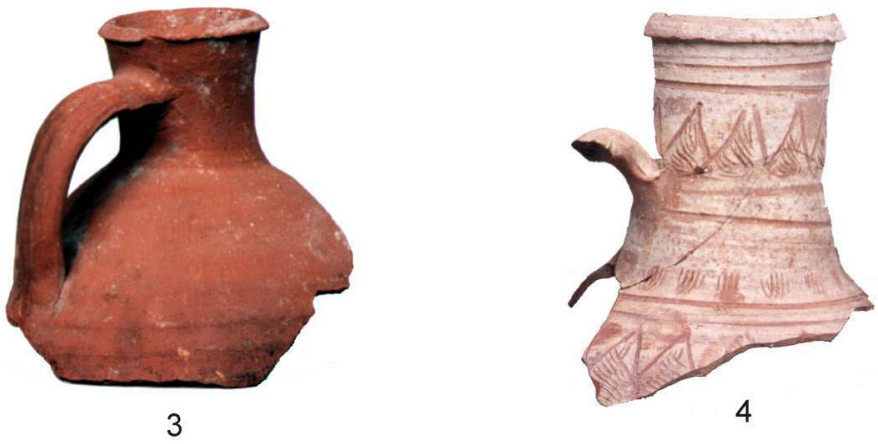

4

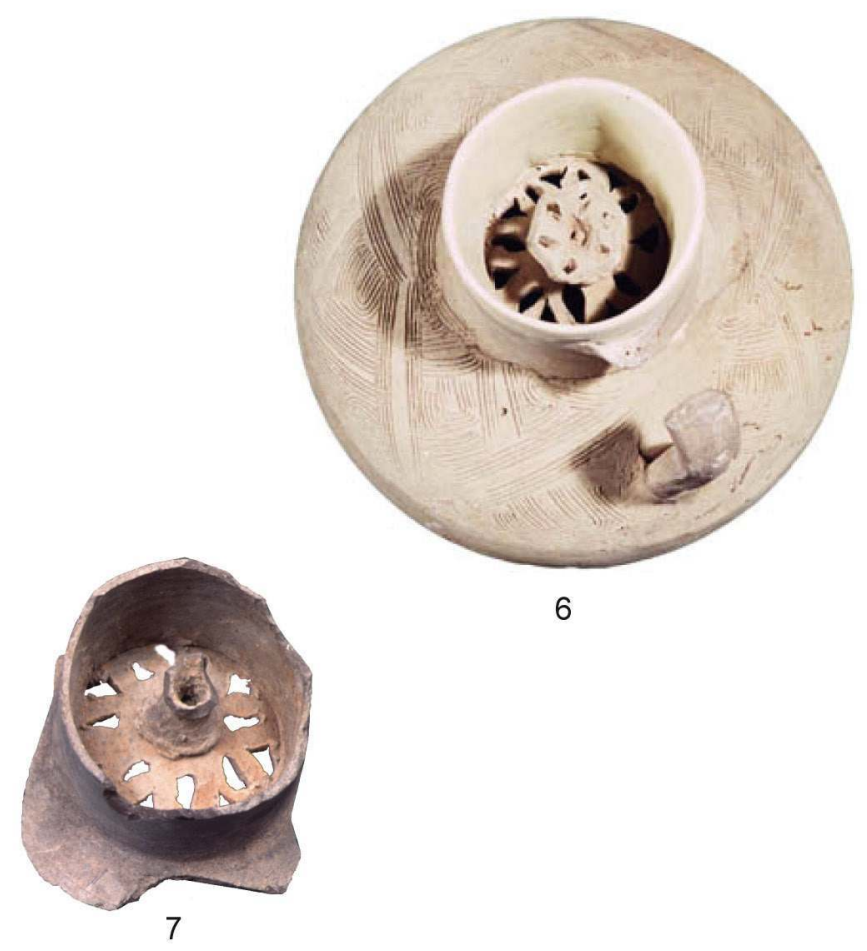

Pl. 2 - Bassin (1) et cruches (2-4); gargoulettes à filtre (5-7). Ech. 1:3. 

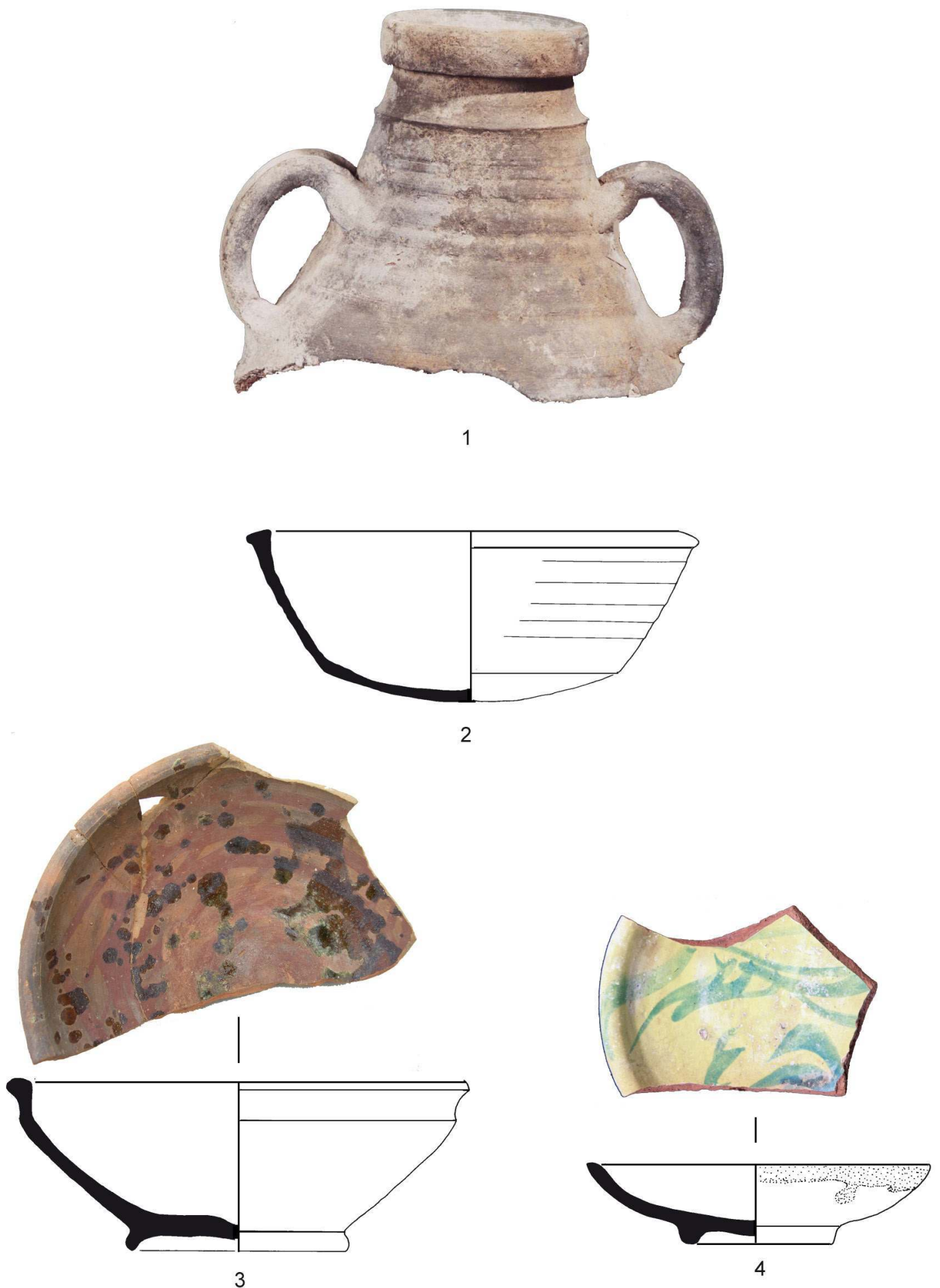

Pl. 3 - Jarre de stockage (1) ; écuelle (2) et coupes de service (3-4). Ech. 1:3. 

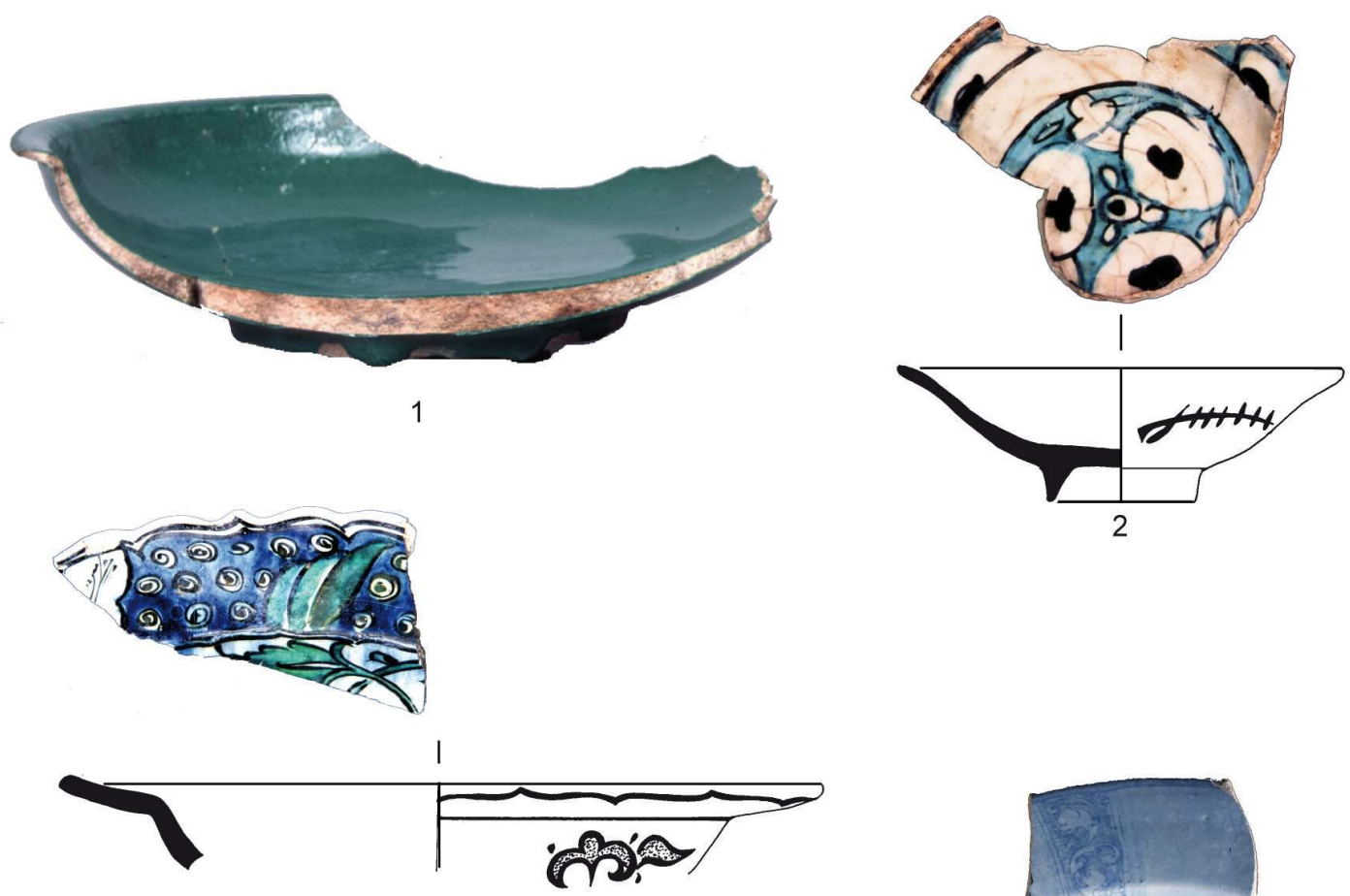

3
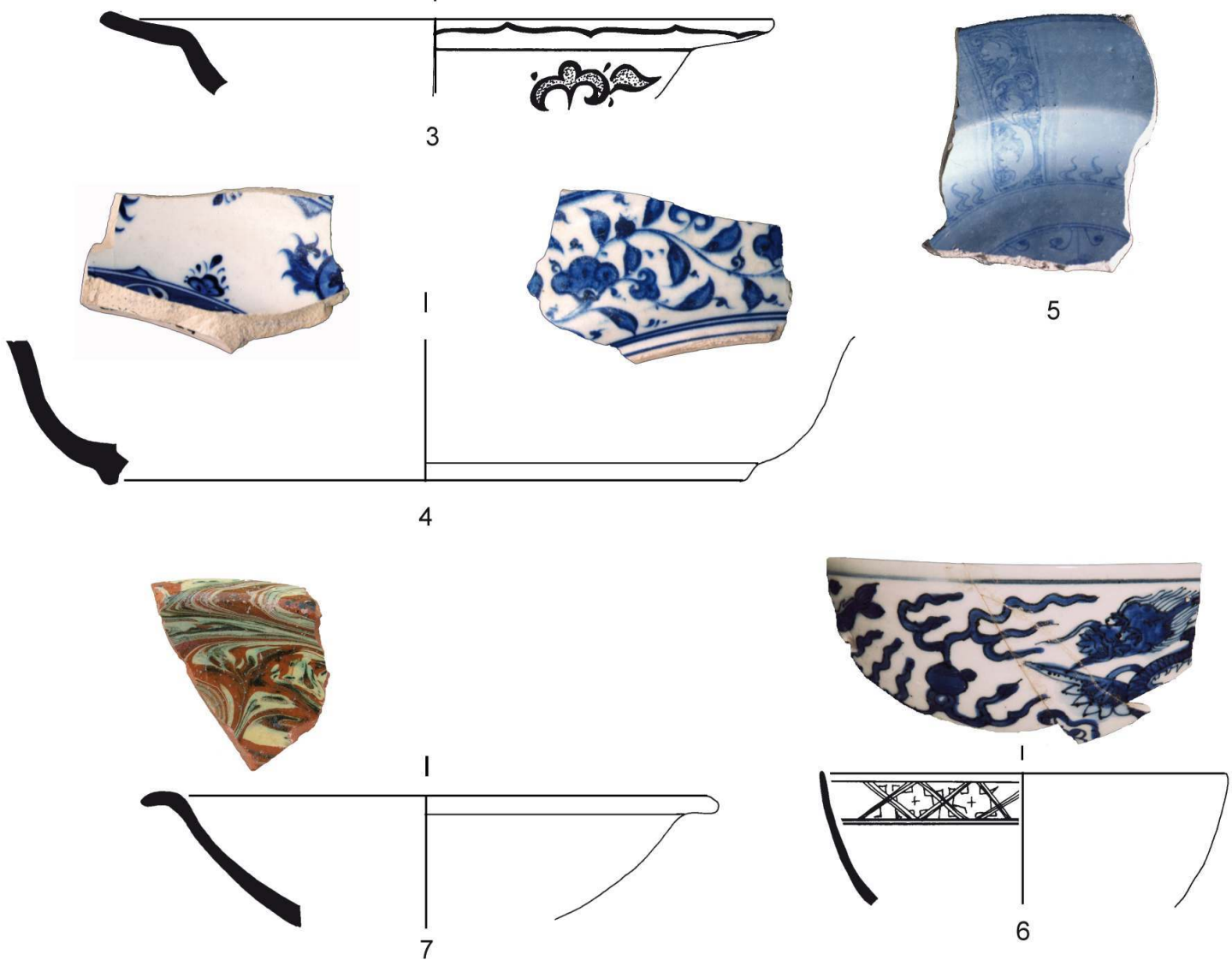

Pl. 4 - Vaisselle de service et de table de Damas (1, 2), d'Iznik (3, 4), de Ligurie (5), de Chine (6) et de Pise (7). Ech. 1:3. 

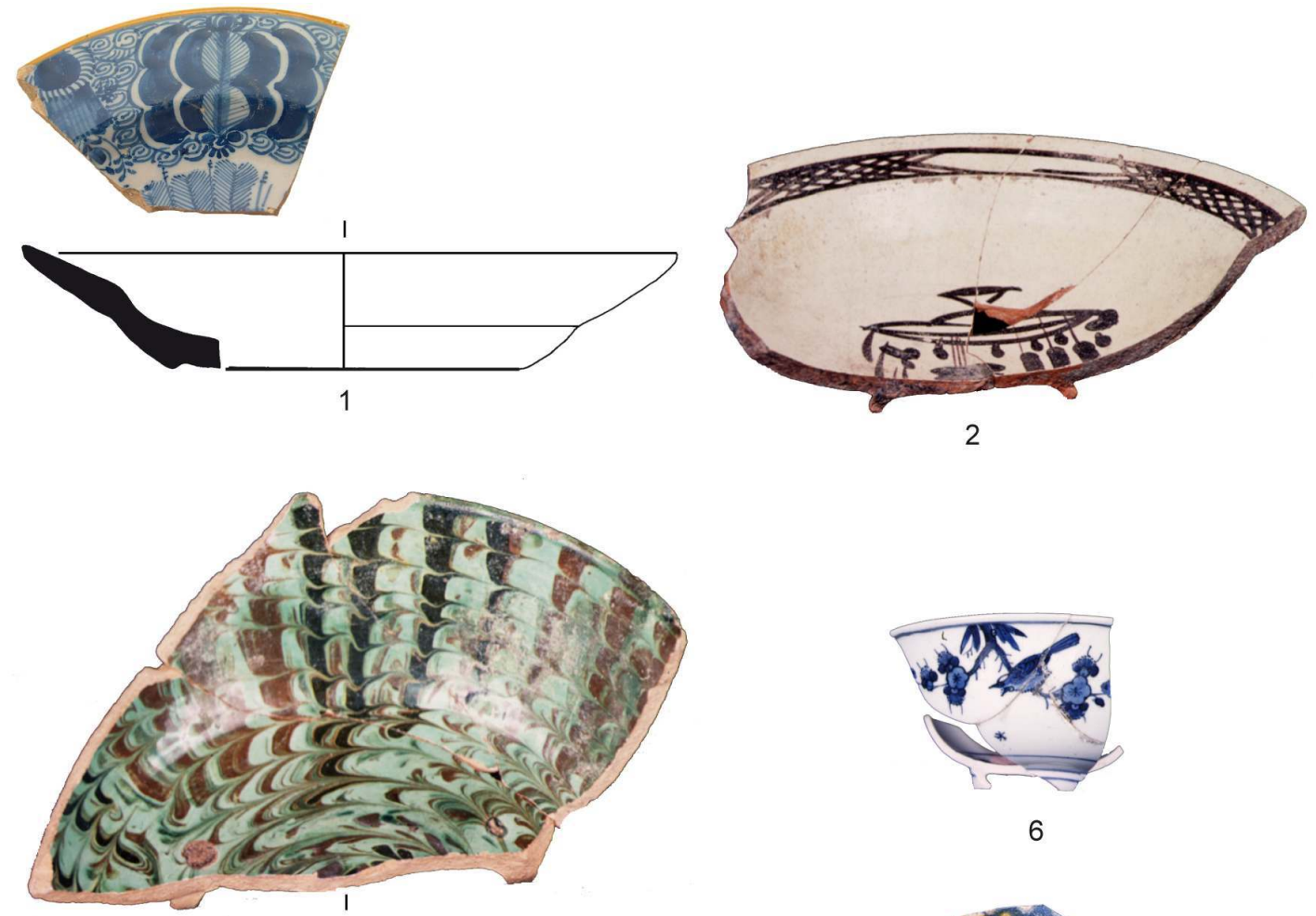

6
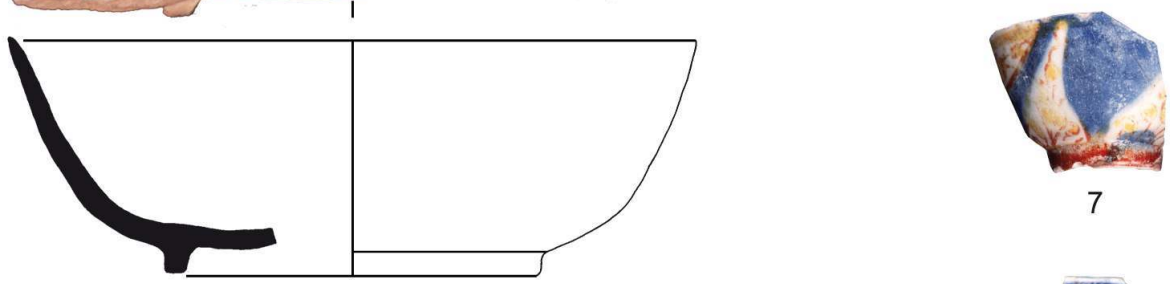

7

3

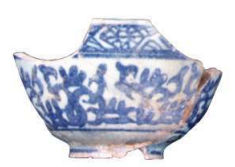

8
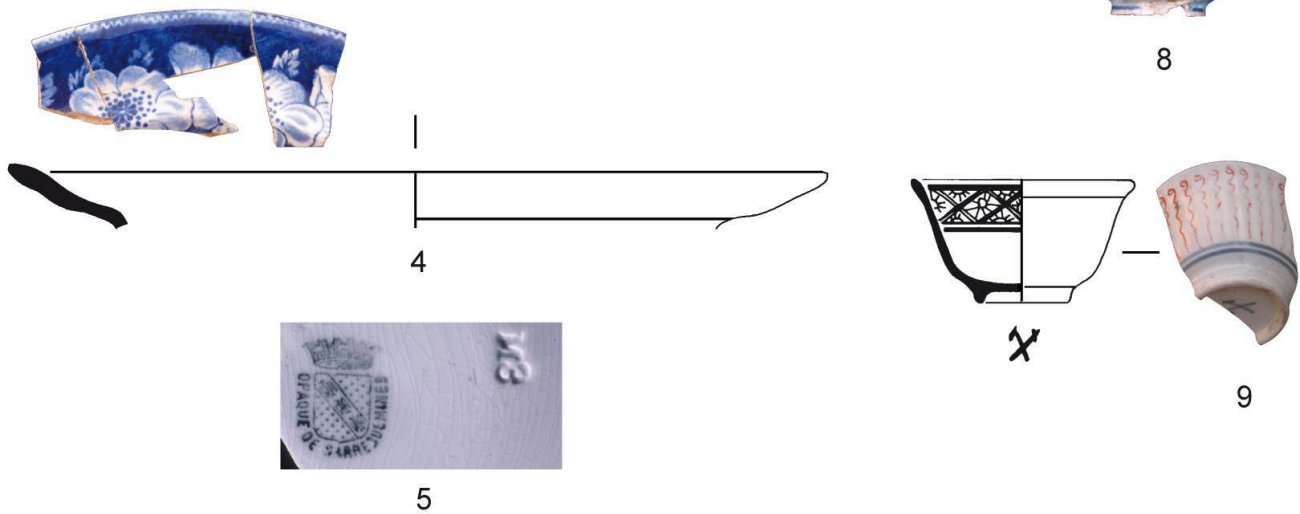

Pl. 5 - Vaisselle de table importée des ateliers de Delft (1), de Canakkale (2) et de Didymotique (3) ; des manufactures de Creil-Montereau (4) et de Sarreguemines (5). Tasses à café de Chine (6), de Perse (7), de Kütahya (8) et de Meissen (9). Ech. 1:3. 

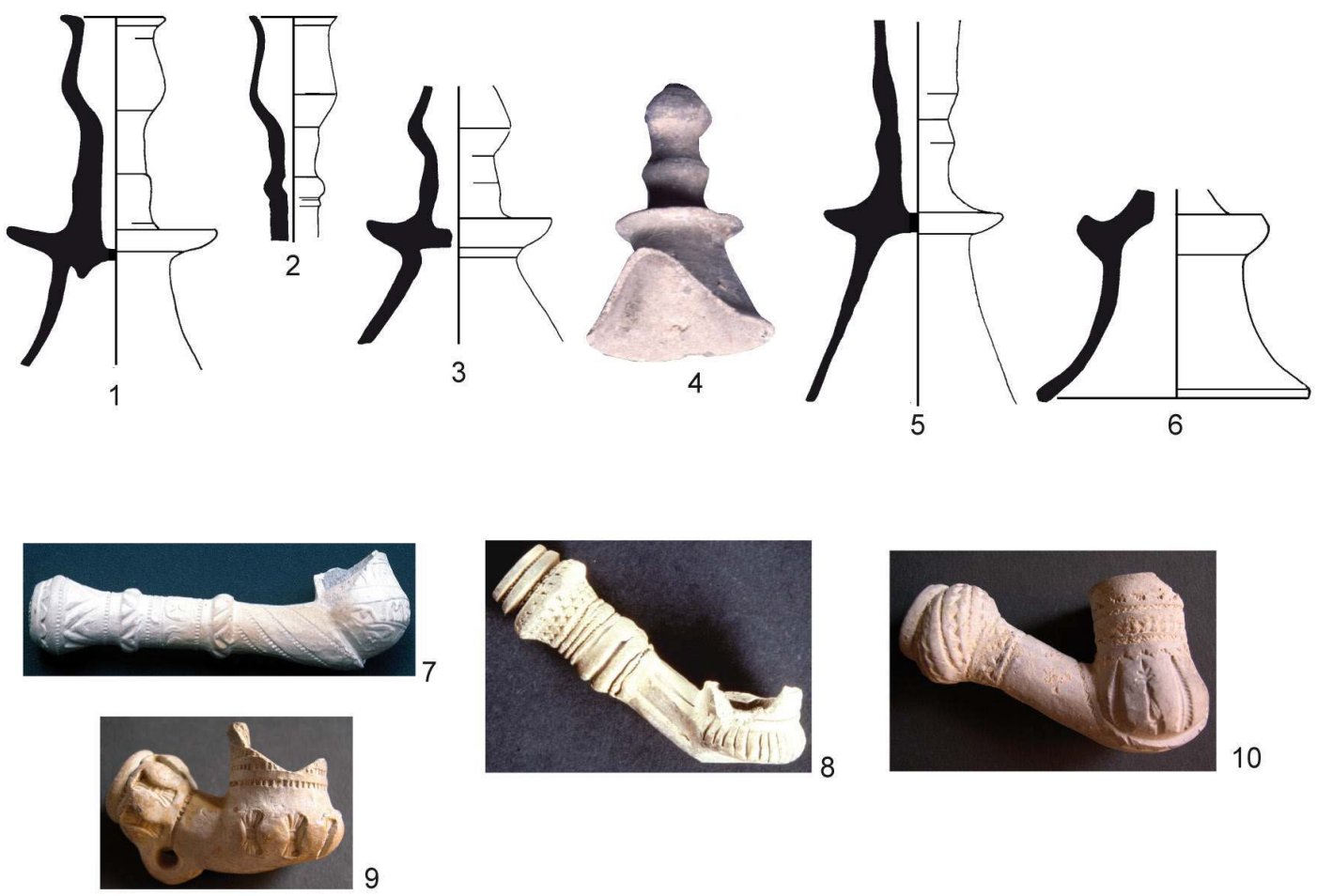

9
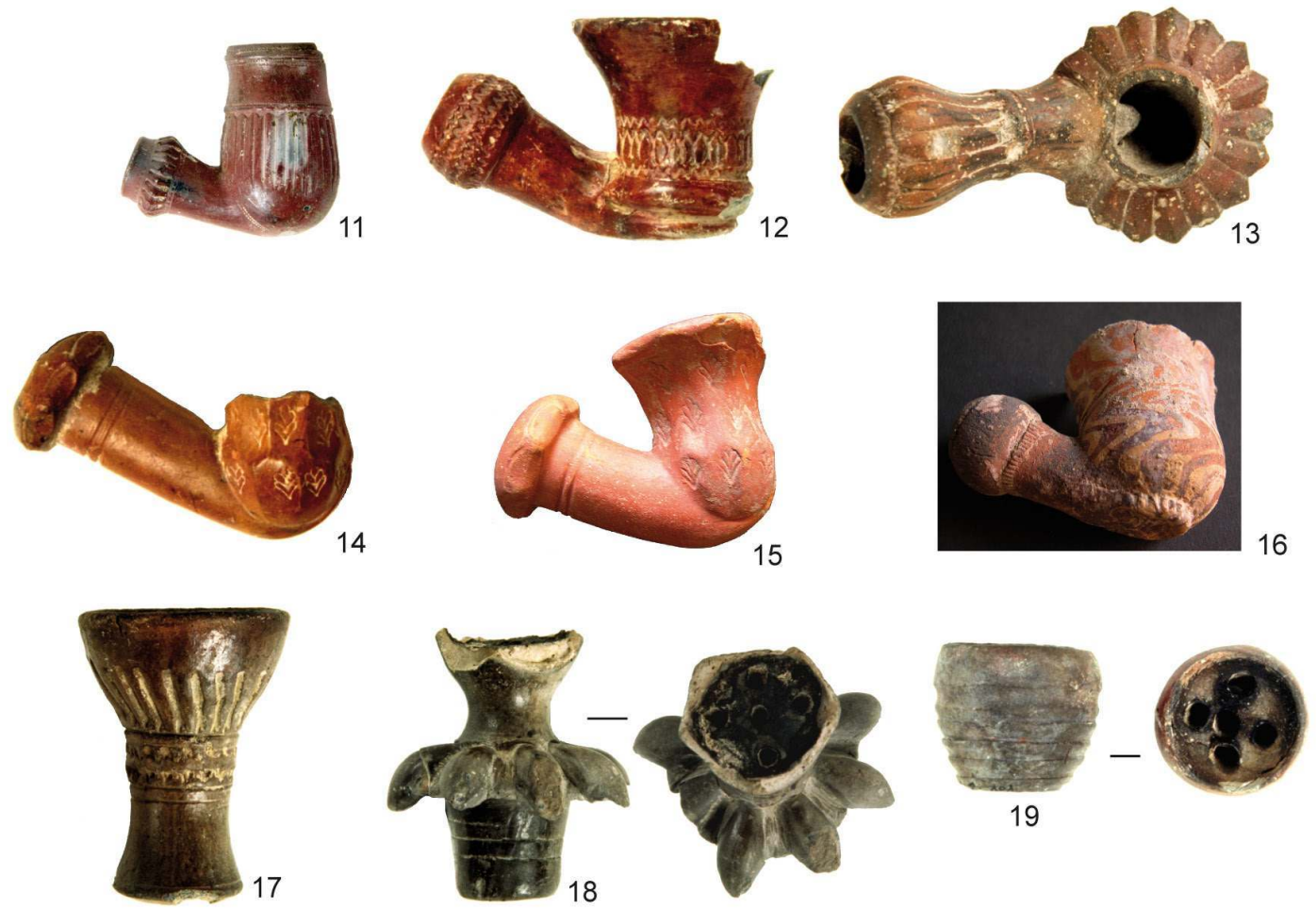

Pl. 6 - Bougeoirs (1-6), Ech. 1:3. Pipes à pâte claire (7-10) ; pipes à pâte rouge (11-16) ; fourneaux de narghilé (17-19). Ech. 1:2. 


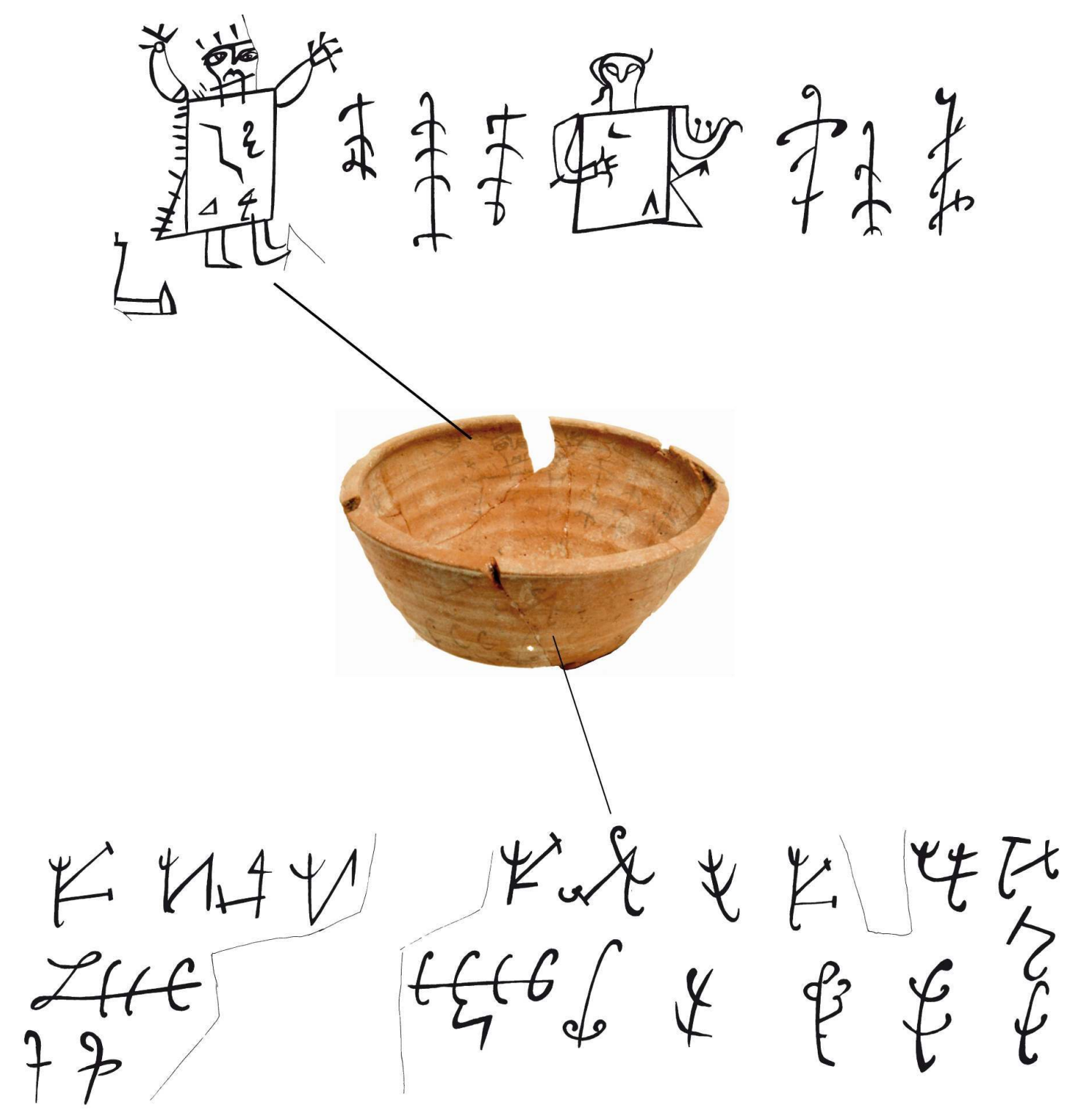

Pl. 7 - « Bol magique ». Ech. 1:3. 